\title{
Horizontal Convective Rolls in Cold Air over Water: Buoyancy Characteristics of Coherent Plumes Detected by an Airborne Radar
}

\author{
Qiong Yang And Bart Geerts \\ Department of Atmospheric Science, University of Wyoming, Laramie, Wyoming
}

(Manuscript received 22 August 2005, in final form 23 December 2005)

\begin{abstract}
Aircraft and airborne cloud radar data are used to describe the vertical structure of the convective boundary layer (CBL) during cold-air outbreaks over Lake Michigan in January 2004. Two days with mesoscale cloud street structure and a day with cellular organization are contrasted. The radar reflectivity and vertical velocity structure of the CBL, as well as the radar-inferred topography of the CBL inversion, are collected along flight legs normal to the cloud streets. High-resolution horizontal and vertical transects of the dual-Doppler airflow field capture horizontal convective roll circulations on one day.

Coherent structures within the CBL are analyzed as echo plumes, updraft plumes, and CBL domes. Only updraft plumes have the characteristics of buoyant thermals. Updrafts are narrower, weaker, and less buoyant on the no-roll day, but the differences in characteristics between two cloud street days are larger than those between the no-roll day and the two cloud street days. The lack of a clear buoyancy signal in echo plumes and under CBL domes is attributed to a temporal phase shift between maximum buoyancy, maximum ice particle size, and maximum overshooting in thermals, and the transience of convective updrafts.
\end{abstract}

\section{Introduction}

Visible satellite imagery often exhibits a cloud street pattern in cold, postfrontal air masses over coastal waters (e.g., Walter and Overland 1984) and the Great Lakes (e.g., Kristovich et al. 2000). Cloud streets also occur over continents (e.g., Weckwerth et al. 1999), where scanning radars have enabled the study of the organization of the convective boundary layer (CBL) even when the CBL is cloud free (e.g., Christian and Wakimoto 1989). Observations, simulations, laboratory experiments, and theory find cloud streets to be oriented in a direction within $\sim 30^{\circ}$ of the mean wind in the CBL (Brown 1972; LeMone 1973; and many others).

In the presence of large surface heat fluxes, turbulent kinetic energy is generated mainly by buoyancy although, as the wind speed increases, turbulence also results from wind shear. Under low wind conditions the CBL is characterized by cellular (3D) convection, referred to as Rayleigh-Bénard convection, which is characterized by an aspect ratio (horizontal scale/

Corresponding author address: Bart Geerts, Department of Atmospheric Sciences, University of Wyoming, Laramie, WY 82071. E-mail: geerts@uwyo.edu vertical scale) of about three (e.g., Houze 1993, p. 64). Convection of this scale is commonly observed in the CBL over water as well as over land (e.g., Miao et al. 2006). A 3D organization may evolve into a $2 \mathrm{D}$ cloud street structure as the wind speed increases (e.g., Kristovich et al. 1999); vice versa, rolls often evolve into cells or unorganized patterns over land during the course of the day as the CBL deepens (Weckwerth et al. 1999).

The most commonly held view of cloud streets is that they are a manifestation of convective organization by wind shear; in other words some eddy kinetic energy is drawn from the mean wind through a dynamic instability (Brown 1972). The linear updrafts in the CBL are generated by organized large eddies (OLEs) in the form of roll vortices (Etling and Brown 1993). Organized motions (also called "coherent structures"), embedded in turbulent flows, transport momentum and/or heat more efficiently than is possible by convection alone (Foster 2005). Observations (Miura 1986) and simulations (Sykes and Henn 1989) concur with theory (Asai 1972) that an increase in low-level wind shear over a "hot" surface (i.e., with large sensible heat fluxes) causes OLEs to transform from 3D cellular to primarily 2D linear convection, evident as cloud streets. The CBL circulation has been described as a helical roll 
circulation, consisting of a series of horizontal roll vortices (Kuettner 1971; Brown 1980; Etling and Brown 1993). The term horizontal convective rolls (HCRs, or "rolls" for short) is more appropriate because the BL is convective; the secondary circulation clusters the buoyant updrafts ("thermals") in linear patterns.

Many numerical and observational studies have confirmed that this mechanism does generate cloud streets (e.g., LeMone and Pennell 1976; Kelly 1982; Chlond 1992; Mourad and Walter 1996; Brooks and Rogers 1997). The primary instability responsible for the rolls scales with CBL depth and has an aspect ratio of 2.83, according to linear theory (Brown 1980). A large range of aspect ratios is observed. Larger values tend to be associated with larger thermal instability (Kelly 1984; Etling and Brown 1993; Atkinson and Zhang 1996; Weckwerth et al. 1997). Young et al. (2002) point out that the aspect ratio of HCRs in cold-air outbreaks over water depends mainly on the CBL depth.

In this study, we use high-resolution airborne cloud radar reflectivity and Doppler velocity data to define regions of convective activity within the $\mathrm{CBL}$, and flight-level thermodynamic data to characterize these regions. Radar data are collected mainly in a vertical plane above and/or below the aircraft, but also in the horizontal plane to the right of the aircraft. Both the CBL circulation and buoyancy characteristics within the CBL are examined. Regarding buoyancy variations, we first select columns of higher radar reflectivity ("echo plumes") or rising motion ("updraft plumes"). We use flight-level data at various levels within the CBL to examine whether these columns tend to be buoyant. Furthermore, we examine buoyancy variations of air under CBL domes (local upward undulations of the CBL top). This analysis is conducted in the vertical plane; thus the conclusions apply to both $2 \mathrm{D}$ (linear) and 3D (cellular) convection; in other words it does not explain the linear alignment of convection. But, because the vertical planes of analysis are roughly normal to the cloud street orientation, the 2D findings are relevant to the interpretation of rolls. Such interpretation must assume that the cross-track dimension is uniform.

Even when rolls are well defined, they are composed of cells that are believed to be largely driven by buoyancy. The superimposed roll circulation may be much weaker, yet sufficient to pull buoyant coherent eddies ("thermals") into linear patterns. In one case study of rolls over Lake Michigan (Kristovich et al. 1999), the mass flux ratio (the ratio of the mean vertical mass flux to the total mass flux in updrafts only, calculated in strips aligned with the rolls) peaks at 0.5 ; that is, the mean roll circulation is comparable to the embedded convective circulations. What appears to be a series of continuous cloud streets from satellite may appear up close-for instance, from an aircraft — as a series of cells that are not obviously aligned. The degree of linearity of cells of rising motion or elevated reflectivity has been studied using the mass flux ratio (Kristovich et al. 1999) and a spatial autocorrelation technique (Weckwerth et al. 1997). The two-dimensionality $(x-z)$ of the radar dataset used here does not allow us to evaluate linearity of convection.

Our primary objectives are (i) to describe the echo and vertical velocity characteristics and finescale kinematic structure of the marine CBL during a cold-air outbreak; (ii) to examine whether the radar signatures of CBL spatial organization (echo plumes, updraft plumes, and local bulges in the CBL depth) tend to have buoyant roots; and (iii) to examine whether the buoyancy properties in rolls differ from those under 3D (cellular) organization.

Following a description of the data sources (section 2 ), the horizontal and vertical kinematic structure of the CBL is described for three cold-air outbreak events (sections 3 and 4, respectively). Next, convective cores are defined in three ways and characterized by means of in situ data (section 5). Sections 6 and 7 discuss and summarize the findings of this study.

\section{Data source and processing}

A small field campaign using the University of Wyoming King Air (WKA) was held over Lake Michigan in January 2004. In this study we use data from the gust probe, various particle measuring probes [Forward Scattering Spectrometer Probe (FSSP), Particle Measuring Systems, Inc. (PMS) 1D-cloud (1D-C), 2D-cloud (2D-C), and 2D-precipitation (2D-P)], the reverse flow temperature sensor (the reverse flow system prevents a temperature bias due to the sublimation of rime), and two humidity sensors (LICOR and chilled mirror). The flight-level vertical air motion is estimated from the WKA gust probe. As part of the routine processing, the aircraft motion is removed from the gust probe raw winds by means of inertial navigation system data and aircraft attitude parameters (Lenschow 1972). Because gust probe velocity components result from the integration of accelerations, their variations are known more accurately than their long-track mean. Typical legmean values in the cases examined here are $0.17 \pm 0.25$ $\mathrm{m} \mathrm{s}^{-1}$. The mean vertical velocity is removed for each flight leg, as is done in flux estimation studies and elsewhere (e.g., Geerts and Miao 2005).

The WKA was equipped with the Wyoming Cloud Radar (WCR), a 3-mm (95 GHz), multiantenna Doppler radar (Pazmany et al. 1994; see the archival site http://atmos.uwyo.edu/wcr/ for details about the WCR). 
Doppler velocities are corrected for aircraft motions using high-frequency aircraft velocity and attitude parameters, yielding the radial particle velocity in a ground-relative coordinate system (Damiani and Haimov 2006). The key radar configuration used for this study is the profiling mode, with fixed antennas looking up and down from the aircraft. The data are sampled at 15-m range intervals, and the first reliable radar gates are centered at $120 \mathrm{~m}$ (nadir) and $105 \mathrm{~m}$ (zenith) from the aircraft, resulting in a $\sim 225 \mathrm{~m}$ blind zone, approximately centered at flight level. Also used in this study, during straight and level flight legs, are the sideantenna, a second side-antenna pointing some $35^{\circ}$ backward from starboard, and a downward antenna pointing some $35^{\circ}$ forward from nadir. The two sideantennas enable dual-Doppler synthesis of the airflow field in the horizontal plane to the right of the aircraft (Damiani and Haimov 2006). The two downwardpointing antennas do the same in the vertical plane below the aircraft. In this campaign only two antennas could be operated simultaneously. All flight-level WKA variables are synchronized to WCR data at a temporal resolution of about $44 \mathrm{~Hz}$.

The radar reflectivity analyzed in this study clearly is the "equivalent" reflectivity $Z_{e}$, computed from power assuming Rayleigh scattering by spherical water droplets. In units of reflectivity, the radar noise increases with the square of radar range. Therefore a simple echo detection filter is applied: radar gates are ignored if the WCR received power is less than two standard deviations above the mean system noise (Geerts and Miao 2005). This filter implies that the minimum detectable reflectivity of WCR is about $-27 \mathrm{dBZ}$ at a range of 1 $\mathrm{km}$.

\section{Horizontal structure of the CBL}

\section{a. Large-scale cloud street structure}

This study analyzes data from four flights conducted over central Lake Michigan during three cold-air outbreaks in late January 2004. Visible satellite and radar reflectivity imagery shows a linear cloud/echo structure on 19 and 22 January, but not on 31 January (Fig. 1). Unfortunately the area of flight operations is too far from the closest Weather Surveillance Radar-1988 Doppler (WSR-88D), in Grand Rapids, Michigan: the echoes are so shallow that the maximum range for the $0.5^{\circ}$-elevation scan is only $\sim 70 \mathrm{~km}$. In any event, the Grand Rapids radar reveals two-three main bands near the eastern shore of the lake on 19 January, and a more fine-banded structure on 22 January. The 19 January echo bands can be seen on the satellite image as well; they are $\sim 10 \mathrm{~km}$ wide and spaced $\sim 15 \mathrm{~km}$ apart.
It was our objective to execute a series of straight and level flight legs normal to the mean CBL wind. This was accomplished within a few degrees. The cloud streets (or echo bands) were oriented some $10^{\circ}$ clockwise of the mean $\mathrm{CBL}$ wind and $10^{\circ}-15^{\circ}$ clockwise of the tracknormal direction (Table 1). On the mornings of 19 and 22 January, three tracks were flown, each track displaced some $20 \mathrm{~km}$ downwind from the previous one. The afternoon flight on 22 January employed just one track. Three tracks with an angular separation of $\sim 60^{\circ}$ and a common center were flown on 31 January. The tracks were 50-70 km long and were all flown at various levels varying from 100 to $1800 \mathrm{~m}$ above the lake surface. The tracks were geographically fixed; that is, the aircraft did not advect with the mean wind. Thus a $\sim 9^{\circ}$ yaw angle was needed to overcome the side wind. For flight legs heading southwestward, this yaw caused the WCR side antenna to look almost exactly along the cloud street orientation. For legs heading northeastward, the cloud street orientation was $\sim 20^{\circ}-25^{\circ}$ clockwise of the WCR side antenna. In addition to the level legs, some ramp aircraft soundings were conducted from near the lake surface to $\sim 500 \mathrm{~m}$ above the CBL top $z_{i}$.

The roll aspect ratio is defined as the spacing between cloud streets (or echo bands) divided by $z_{i}$. The latter can be accurately estimated using WCR profiles (see below). It increases with fetch across the lake but is fairly level near the flight operations at the downstream end of the lake. The cloud street spacing is more difficult to estimate. The simplest method divides the number of echo bands by the cross distance (Table 1) in a region with WSR-88D echoes as close as possible to the flight tracks. This spacing (Table 1) varied little during the flight period.

Another method is based on the spectral analysis of flight-level vertical air velocity $w$, potential temperature $\theta$, mixing ratio $q$, and along-track wind $v_{\text {nat. }}$. The frequency of the dominant peak in the spectrum is converted to distance using the aircraft's ground-relative speed. Anomalies of $\theta$ and $q$ should be in phase with $w$ in an idealized helical roll circulation, so their cospectra are examined (e.g., LeMone and Pennell 1976; Weckwerth et al. 1996). The quadrature spectra are examined for the correlation between $w$ and along-track horizontal velocity $v_{\text {nat. }}$. The dominant wavelengths for the $(\theta, w)$ and $(q, w)$ cospectra and the $\left(v_{\text {nat }}, w\right)$ quadrature spectra were inferred for eight flight legs within the CBL, four from each of the flights on 22 January. The average and standard deviation listed in Table 1 for 22 January thus are based on 24 values. The range of spectrally inferred wavelengths corresponds well with the observed echo band spacing in the vicinity on 22 Janu- 

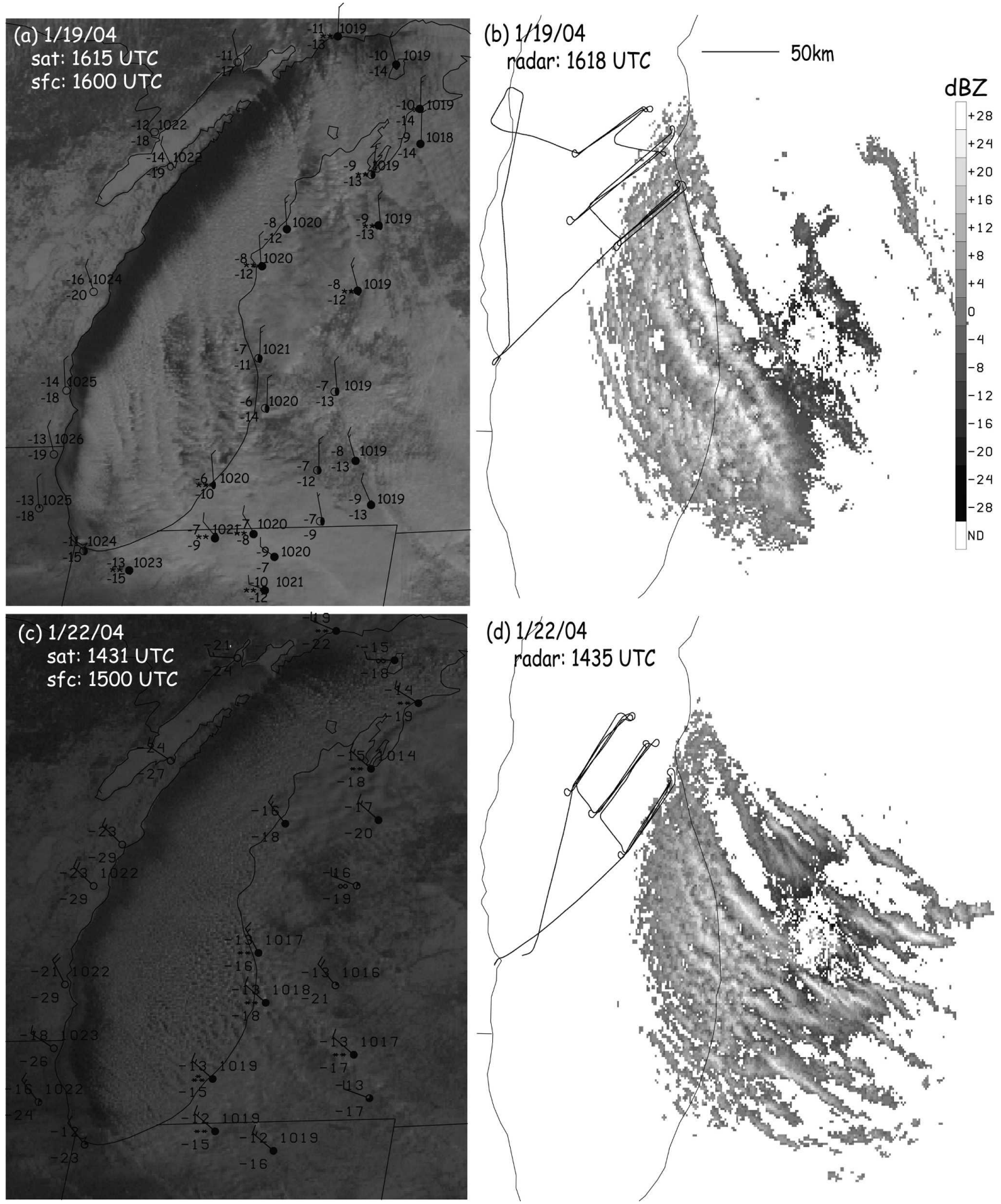

FIG. 1. Geostationary Operational Environmental Satellite-12 (GOES-12) visible images and $0.5^{\circ}$-elevation Grand Rapids WSR-88D reflectivity images for (a), (b) 19 Jan; (c), (d) 22 Jan, morning; (e), (f) 22 Jan, afternoon; and (g), (h) 31 Jan 2004. The WKA flight tracks used in this study are shown in black lines on radar reflectivity images.

ary (Table 1$)$, both in the morning and in the afternoon. The resulting aspect ratio $(3.2 \pm 1.8)$ is consistent with theory and observations (e.g., Young et al. 2002). Thus the 22 January cloud streets are considered to be "normal."
The 19 January cloud streets tend to be more widely and more irregularly spaced than on 22 January. Multiple minor peaks but no single dominant peak emerged in the spectral analyses on 19 January; thus no number is shown in Table 1 . The CBL depth $(\sim 1.4 \mathrm{~km})$ is also 



FIG. 1. (Continued)

greater than on any other day. The aspect ratio is about 10 , which is unusually large for cold-air outbreaks over water (Young et al. 2002).

\section{b. Finescale echo and velocity structure}

At least one horizontal WCR transect was collected on each flight. The finescale horizontal patterns are dissimilar on the two days with cloud streets (Fig. 2). With a maximum range of $9 \mathrm{~km}$, the WCR provides a rather myopic view, insufficient to reveal the broader structure. On 19 January the echo cells are rather poorly arrayed in a north-south direction, and the echo bands are widely spaced, consistent with WSR-88D and satellite data (Table 1 ). The cells do not clearly connect 
TABLE 1. WKA sampling statistics and mesoscale cloud/echo characteristics in the area of flight operations. Angles increase clockwise from north. The CBL depth is denoted as $z_{i}$.

\begin{tabular}{|c|c|c|c|}
\hline & 19 Jan (A.M.) & $\begin{array}{l}22 \text { Jan } \\
\text { (A.M. and P.M.) }\end{array}$ & 31 Jan (A.M.) \\
\hline Cloud/echo organization & Linear & Linear & Cellular \\
\hline Mean wind speed at $\sim 0.5 z_{i}\left(\mathrm{~m} \mathrm{~s}^{-1}\right)$ & 13.0 & 13.7 & 5.9 \\
\hline Mean wind direction at $\sim 0.5 z_{i}$ & $333^{\circ}$ & $313^{\circ}$ & $287^{\circ}$ \\
\hline Cloud street orientation & $343^{\circ} \leftrightarrow 163^{\circ}$ & $322^{\circ} \leftrightarrow 142^{\circ}$ & N/A \\
\hline Flight track orientation & $240^{\circ} \leftrightarrow 60^{\circ}$ & $220^{\circ} \leftrightarrow 40^{\circ}$ & $\begin{aligned} 220^{\circ} & \leftrightarrow 40^{\circ}, \\
339^{\circ} & \leftrightarrow 159^{\circ}, \\
102^{\circ} & \leftrightarrow 282^{\circ}\end{aligned}$ \\
\hline Flight track's proximity to the cloud-street-normal direction & $\sim 13^{\circ}$ & $\sim 12^{\circ}$ & N/A \\
\hline Mean WCR-derived $z_{i}$ along flight track $(\mathrm{km})$ & 1.37 & 1.10 & 0.57 \\
\hline $\begin{array}{l}\text { Echo band spacing, estimated from Grand Rapids WSR-88D } \\
0.5^{\circ} \text { reflectivity scans }(\mathrm{km})\end{array}$ & $10-18$ & $2.5-5.3$ & N/A \\
\hline $\begin{array}{l}\text { HCR spacing, estimated from the spectral analysis of flight-level } \\
\text { data }(\mathrm{km})\end{array}$ & N/A & $3.2 \pm 2.0$ & N/A \\
\hline Cloud street aspect ratio & $7: 1$ to $13: 1$ & $2: 1$ to $5: 1$ & N/A \\
\hline $\begin{array}{l}\text { Total flight track distance of the WCR/WKA data used in the } \\
\text { analysis of plumes and CBL domes }(\mathrm{km})\end{array}$ & 187 & 384 & 110 \\
\hline
\end{tabular}

into a band. The gaps are narrow and more continuous. The Doppler velocity (Fig. 2b) is dominated by the cross-track wind of about $13 \mathrm{~m} \mathrm{~s}^{-1}$ (consistent with Table 1). Considerable flow variations occur in the radial direction, which is essentially the cloud street direction. Radial confluence occurs in some cells, but not all, possibly because the flight level is close to the level of nondivergence near $0.5 z_{i}$.

On 22 January the echo streets are better defined and more closely spaced. One orientation of echo cells is essentially aligned with the $y$ axis, consistent with the orientation listed in Table 1. The eye picks up another orientation, roughly east-west, in the reflectivity field and especially the radial velocity field (Fig. 2d). The flow appears to be confluent not at but between the main echoes at this flight level $\left(0.61 z_{i}\right)$. We do not have a flight leg along the large-scale cloud street orientation $\left(322^{\circ}\right.$; see Table 1$)$, so we do not know how strong the secondary circulation is across $322^{\circ}$, but clearly the speed variations of the northwesterly wind are consistent with the echoes along a secondary axis that is rotated counterclockwise some $45^{\circ}$ relative to the largescale cloud street orientation. The circulation around this axis appears to have a similar aspect ratio as the primary roll circulation. More narrow bands with roughly a northwest-southeast orientation can be seen on 19 January (Fig. 2a; mainly toward the left), and they too modulate the horizontal wind (Fig. 2b). It is not clear what causes the secondary bands on both days; possibly they are aligned with the surface wind near the upwind shore (shown below). On both days we saw surface-layer streaks highlighted by steamfog over open water near the western shore.
Dual-Doppler-synthesized horizontal winds are available for another flight leg on 22 January (Fig. 3). This flight leg has nearly the same orientation as in Fig. $2 \mathrm{c}$ and is some $20 \mathrm{~km}$ downstream and some $45 \mathrm{~min}$ later (Fig. 1d). The echo bands are clearly aligned with the $y$ axis, and the secondary east-west orientation (Figs. 2c,d) is not apparent in the echoes or the wind field. The wind field varies at the same wavelength as the echoes, as is evident in the derived convergence and vorticity fields (not shown). The axis of cyclonic vorticity is phase shifted $\sim 90^{\circ}$ relative to the reflectivity. This vorticity is due to stronger northwesterly winds in the echo bands, compared to the gaps. This may be because of northwest shear across the CBL top (Fig. 4b): echo bands may mix in more northwest momentum from above the CBL. This suggests that convective overturning within cloud streets is rapid compared to the mean transverse circulation: the helical flow would carry lowmomentum air up in the cloud streets (e.g., Foster 2005). This momentum variation, if it mixed down to the water level, may affect the magnitude of the surface fluxes. This is in addition to surface wind and flux enhancement by the helical roll circulation (e.g., Mourad and Walter 1996).

\section{Vertical structure of the CBL}

\section{a. Soundings}

Both aircraft and radiosonde data are used to construct vertical profiles of the lower troposphere upstream of and over Lake Michigan (Fig. 4). The aircraft-based $(\theta, q)$ profiles reveal significant horizontal 


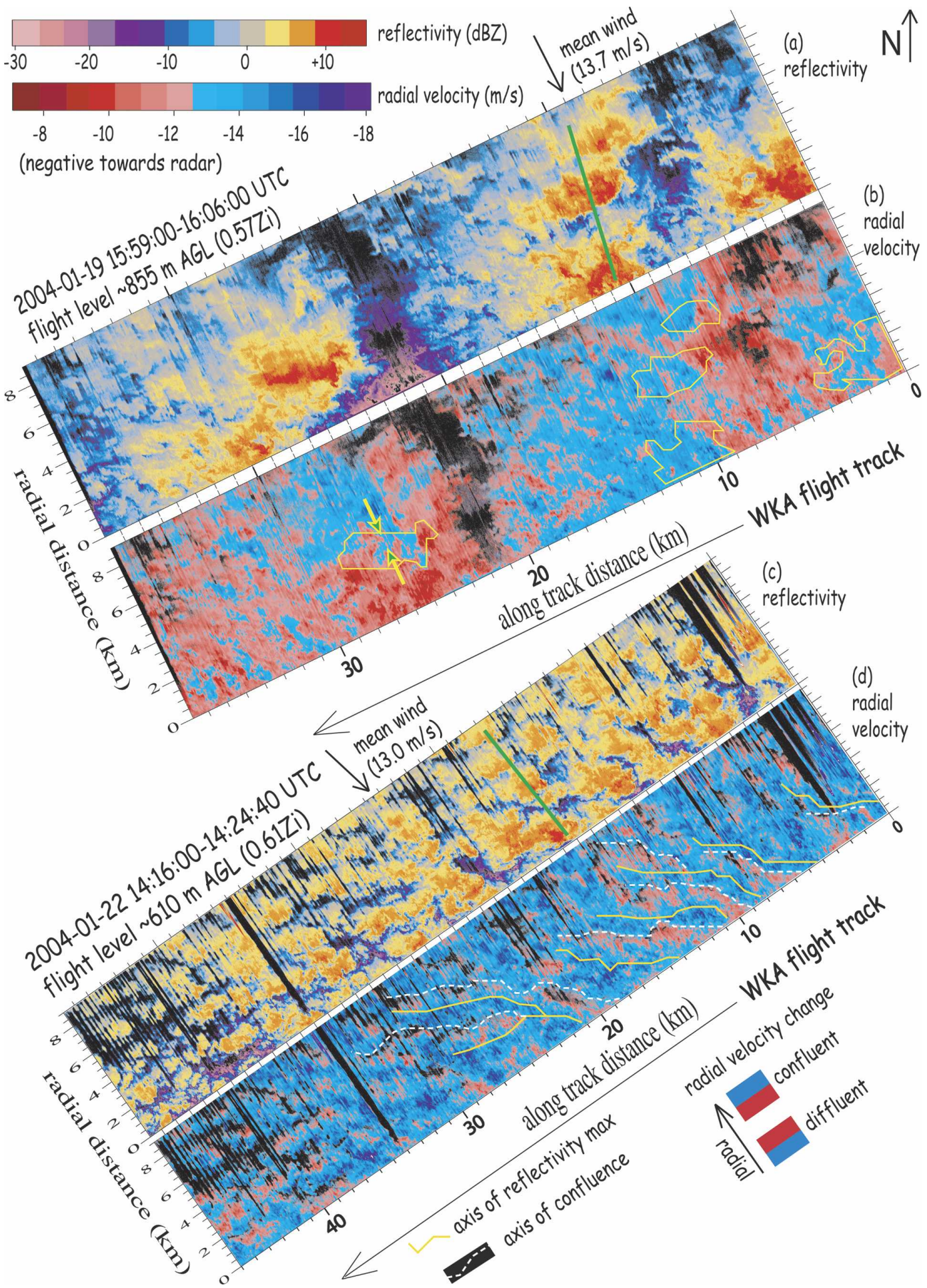

FIG. 2. Near-horizontal views of (a), (c) radar reflectivity and (b), (d) WCR radial velocity on (top) 19 January and (bottom) 22 January. The axes are range from aircraft (minus 105-m blind zone) and distance along the track. The flight level is near $1 / 2 z_{i}$. Nevertheless the rolling of the aircraft caused the radar beam to sometimes intersect either the lake surface or $z_{i}$. This explains the vertical stripes, whose number and width increases with range. The images have a 1:1 aspect ratio. The "mean wind" vectors and the cloud street orientation [shown as green lines in (a) and (c)] are as given in Table 1. The yellow contours in (b) indicate the location of the main echoes, and the yellow arrows in (b) illustrate confluent flow. 


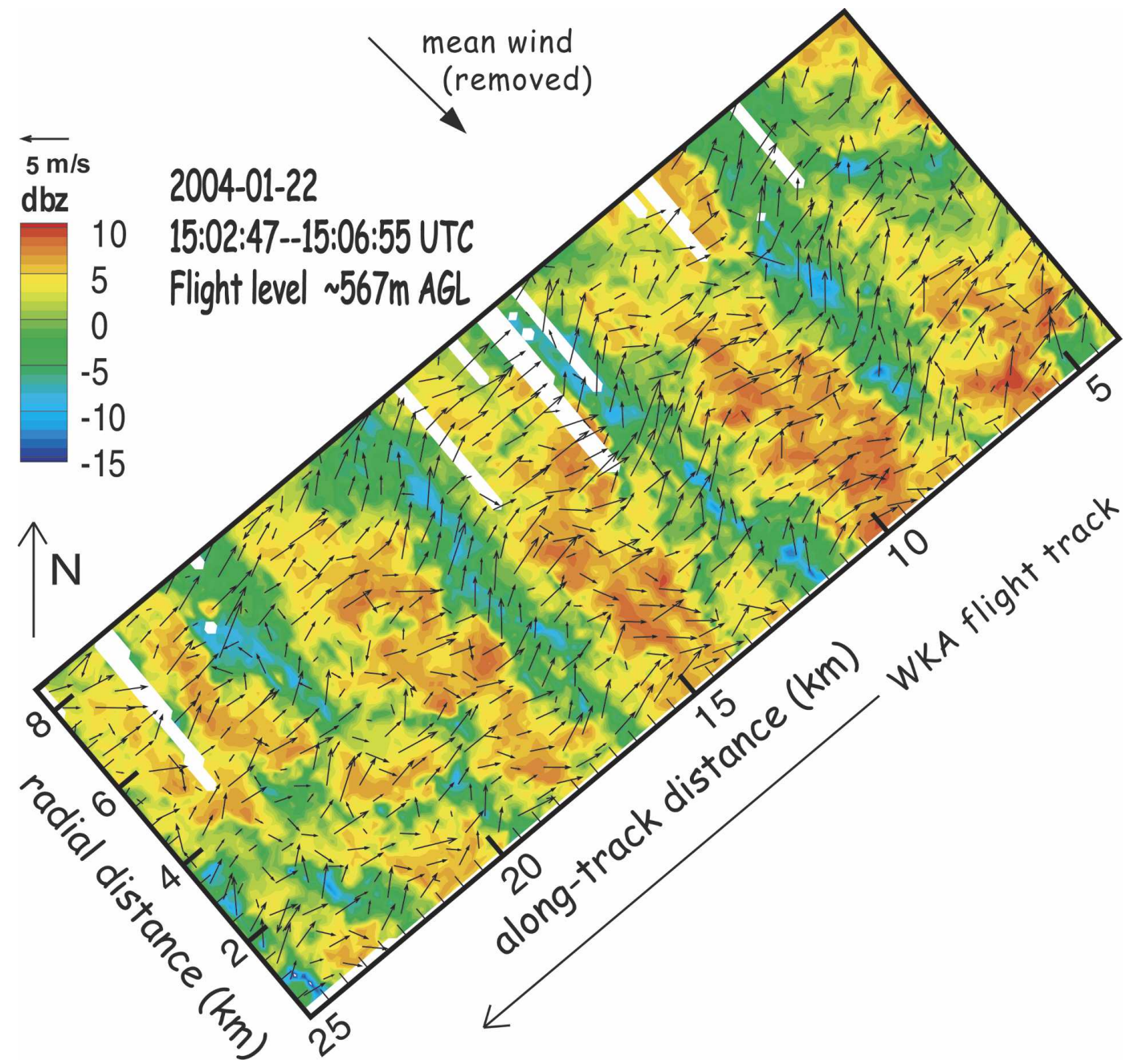

FIG. 3. (a) Reflectivity and wind vectors (inferred from WCR horizontal-plane dual-Doppler analysis) based on a flight leg along the southernmost track in Fig. 1d. The axes are the same as in Fig. 2, and the grid resolution is $504 \times 422 \mathrm{~m}^{2}$. The wind vectors are relative to the flight-level mean wind $(-1.4,-14.4) \mathrm{m} \mathrm{s}^{-1}$. The aspect ratio is $1: 1$.

variability along the ascending flight track, as evidenced by layers that appear to be absolutely unstable. On 19 January (Fig. 4a) very stable conditions occurred upstream of the lake, especially in the lowest $200 \mathrm{~m}$. The reduced stability between 200 and 400 m may imply a residual CBL generated farther upstream, over western Lake Superior. At a fetch of about $150 \mathrm{~km}$, a well-capped mixed layer was present with $z_{i} \approx 1350 \mathrm{~m}$ AGL. Over this fetch the near-surface $\theta$ increases about $9 \mathrm{~K}$ and the near-surface $q$ doubles to $\sim 1.5 \mathrm{~g}$ $\mathrm{kg}^{-1}$. The $q$ values in the downwind CBL clearly decrease with height above $500 \mathrm{~m}$ to $\sim 0.9 \mathrm{~g} \mathrm{~kg}^{-1}$ near the CBL top, which is consistent with the saturation mixing ratio for the observed temperature profile between 500 $\mathrm{m}$ and the CBL top (not shown). The wind profile is more uniform on the downwind side than the upwind side of the lake, consistent with the development of the CBL. A low-level jet remains weakly defined around $300 \mathrm{~m}$ AGL.

The Green Bay, Wisconsin, 1200 UTC radiosonde data are used to depict the upwind conditions on 22 and 31 January, because of the lack of suitable WKA sounding. On 22 January the forward video camera shows the WKA entering the cloudy CBL at least twice during its spiral ascent near the eastern shore of the lake; this explains the large departures of $\theta$ and $q$ near the CBL top $\left(z_{i} \approx 1100 \mathrm{~m}\right.$ AGL, Fig. $\left.4 \mathrm{~b}\right)$ and suggests that the CBL top undulates significantly. Near-surface $\theta$ values increase about $8 \mathrm{~K}$, as on 19 January, but the near-surface $q$ increases to about half the value observed downwind on 19 January. This difference can be explained by the colder air mass on 22 January $(\sim 7 \mathrm{~K}$ 

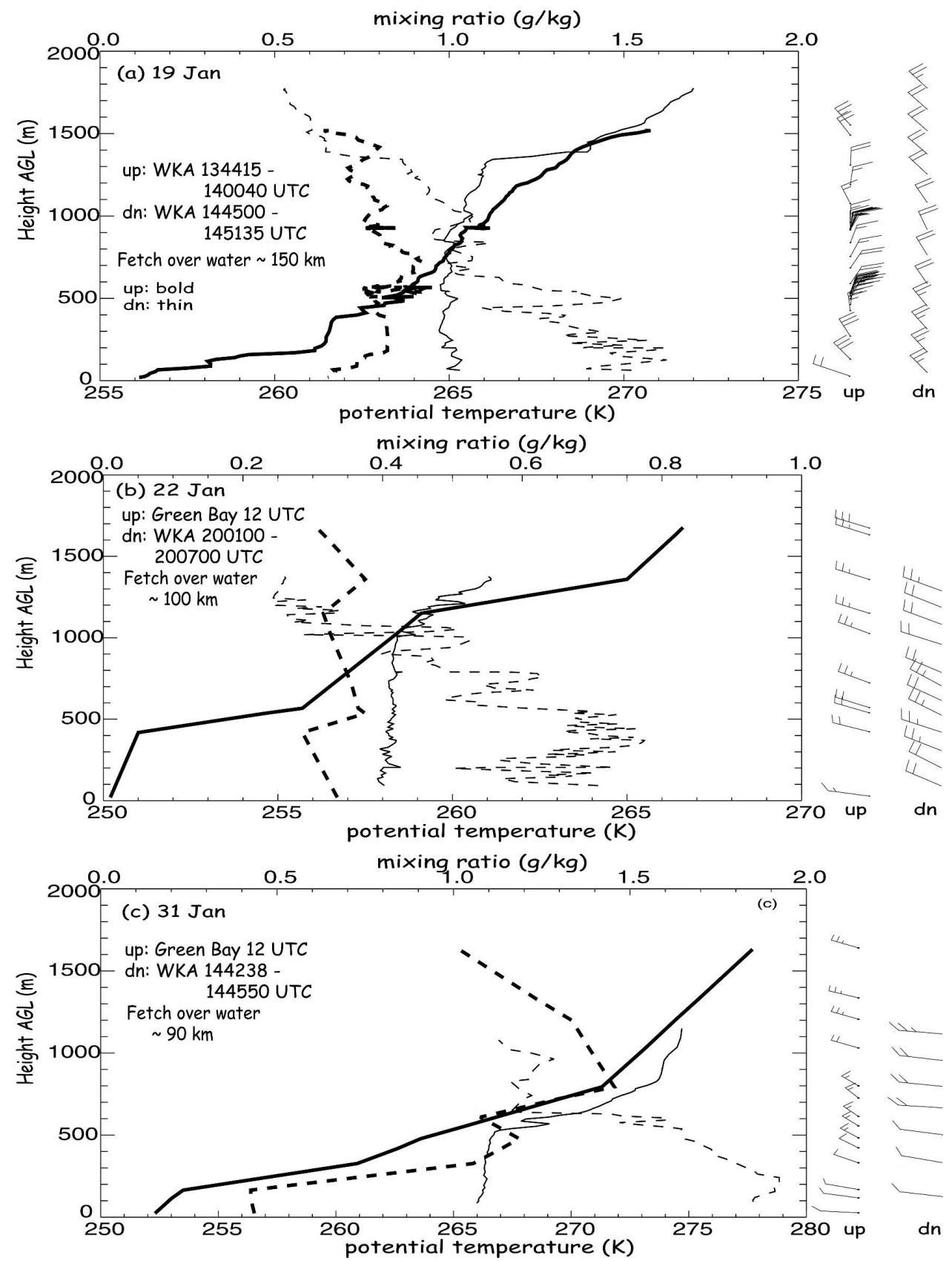

FIG. 4. Profiles of potential temperature $\theta$ (solid), mixing ratio $q$ (dashed), and wind for (a) 19 January, (b) 22 January, and (c) 31 January. The bold lines apply to the upwind side of Lake Michigan ("up"), over Sheboygan for (a) and Green Bay for (b), (c). The thin lines (downwind or "dn") apply at a fetch over water as indicated, in all cases $10-30 \mathrm{~km}$ off the eastern shore. The downwind soundings and the 19 Jan upstream sounding are inferred from WKA data. The operational Green Bay soundings are of rather low resolution. The WKA data are averaged at 25 -m vertical increments for $\theta, q$, and wind. Wind profiles are plotted at an interval of $\sim 100 \mathrm{~m}$.

colder upstream of the lake). The 19 January air mass has a more meridional track across Lake Michigan (Fig. 4, Table 1) and appears to have been moistened by passing over Lake Superior first, as is evident in the higher $q$ values upstream (and downstream, above $z_{i}$ ). On 22 January $q$ decreases with height above $\sim 500 \mathrm{~m}$ AGL, as on 19 January, and several times along the WKA spiral descent, $q$ dips well below saturation mix- 
ing ratio $q_{s}$ (not shown), suggesting that the cloudiness is intermittent.

On 31 January, a day without cloud streets (Fig. 1), the near-surface winds are far weaker (Fig. 4c, Table 1) than on the two other days, both upstream and within the CBL over water. A shallow but strong inversion prevails in the upstream area, some $20 \mathrm{~K} \mathrm{~km}^{-1}$ in the lowest kilometer, as opposed to $\sim 10 \mathrm{~K} \mathrm{~km}^{-1}$ on the two days with cloud streets. At $200 \mathrm{~m}$ AGL, the values of $\theta$ and $q$ increased about $13.5 \mathrm{~K}$ and $1.3 \mathrm{~g} \mathrm{~kg}^{-1}$ across the $\sim 90 \mathrm{~km}$ fetch. These changes are $\sim 5 \mathrm{~K}$ and $\sim 0.8 \mathrm{~g} \mathrm{~kg}^{-1}$ larger than on the two days with rolls; however, the heating and moistening is contained in a shallower layer $\left(z_{i} \approx 550 \mathrm{~m} \mathrm{AGL}\right)$. The mixing ratio decreases above $250 \mathrm{~m}$ AGL, consistent with a low cloud base as confirmed by FSSP data.

In summary, the definition and depth of the CBL developing over open water during cold-air outbreaks, and the amount of warming and moistening, are generally consistent with previous studies (e.g., Kelly 1982; Kristovich et al. 2003). Near-surface winds increase and wind shear within the CBL decreases as the CBL develops. The $q$ decrease in the upper CBL is consistent with the observed cloudiness.

\section{b. Reflectivity profiles and $C B L$ depth}

The CBL was generally rich in small snow crystals over its entire depth, and thus the WCR could clearly detect the CBL top as a level of large reflectivity gradient (Fig. 5). On average this level, referred to as $z_{i^{-}}$ -wCR, is larger on 19 January than on 22 January, and larger on 22 January than on 31 January, consistent with sounding data (Fig. 4). On all days reflectivity "plumes" were encountered, that is, regions of higher reflectivity interspersed with narrow regions of weaker reflectivity. These plumes are generally associated with a slightly elevated $z_{i-\text { WCR }}$ (e.g., Fig. 5c).

These "gap" (or interplume) regions are not devoid of echo, suggesting that the time scale of convective/ helical circulations is short compared to that of snow fall out. Radiance data from a broad-beam nadirpointed infrared $(12 \mu \mathrm{m})$ sensor on the WKA are used to determine whether gaps in the clouds existed through which the lake skin temperature could be sensed on flight legs above the CBL. While the WCR essentially profiles snow amount (especially the larger snowflakes), a reduction in upwelling IR blackbody temperature is more sensitive to the concentration of cloud particles between lake surface and flight level. An example IR temperature trace is shown in Fig. 5e. Significant variations occur in upwelling IR temperature, and maxima correspond with the echo gaps. The highest IR temperature readings $\left(\sim-2^{\circ} \mathrm{C}\right)$ are only slightly below lake surface temperature. Cloudiness was extensive, but on all three days we occasionally spotted the lake surface on above-CBL flight legs.

An objective technique is used to determine $z_{i_{-} \text {wCR }}$ from the WCR reflectivity profiles, low-pass filtered to a resolution of $10 \mathrm{~s}$ or about $800 \mathrm{~m}$ (Miao et al. 2006). This resolution captures the broader domes associated with cloud streets, but it ignores the finescale topography evident in all three transects in Fig. 5. The purpose of the filter is to examine variations in $z_{i}$ across the lake and due to linear or cellular convection at least $800 \mathrm{~m}$ in size.

The variation of $z_{i \_ \text {WCR }}$ with fetch is unambiguous (Fig. 6) and is consistent with previous observations (e.g., Kelly 1984; Kristovich et al. 2003). There is some suggestion that the depth increase is more rapid at short fetch and slower at longer fetch, especially on 22 January. Ignoring the fetch dependence, significant variation of $z_{i-W C R}$ remains. This can partly be attributed to the exact location of the track (Fig. 6a), or to the time of day on 22 January (Fig. 6b). On this day the CBL was slightly deeper in the afternoon. Clearly the $z_{i_{-} \text {WCR }}$ scatter at a given fetch is at least in part tied to the CBL dynamics (Fig. 5), as will be explored further. Thermodynamic data are not available at the same density as the WCR data, but flight-level observations indicate a clearly defined stratocumulus cloud top on all flights and a jump in $q$ and $\theta$ every time the cloud top was penetrated. Thus the real (thermodynamically defined) CBL depth, $z_{i_{-} \mathrm{TH}}$, probably varies as much as $z_{i_{-} \mathrm{WCR}}$. It corresponds well with the range of $z_{i_{-} \mathrm{WCR}}$ values at the corresponding fetch (Fig. 6).

No stationary wave pattern can be seen in the $z_{i_{-} \mathrm{WCR}}$ estimates from various flight legs used to composite Fig. 6. CBL depth variations (and associated CBL dynamics) appear to be rather transient, even on 19 January when the downstream eastern shore of Lake Michigan may have affected the location and intensity of the major snowbands. Echo plumes along one transect do not match with those of the subsequent transect along the same geographically fixed track on either 19 or 22 January. WSR-88D (Fig. 1) and WCR (Fig. 2) reflectivity maps reveal large along-band variability (Fig. 2). Thus the main reason that WCR vertical transects cannot be matched appears to be that the strong cross wind (Table 1) rapidly advects a different cell pattern. It is possible also that cells evolve rapidly. Clusters of cells can be followed in WSR-88D reflectivity animations for up to an hour, but their shape changes continuously, probably because convective updrafts emerge and collapse. As will be shown later, the question of tran- 

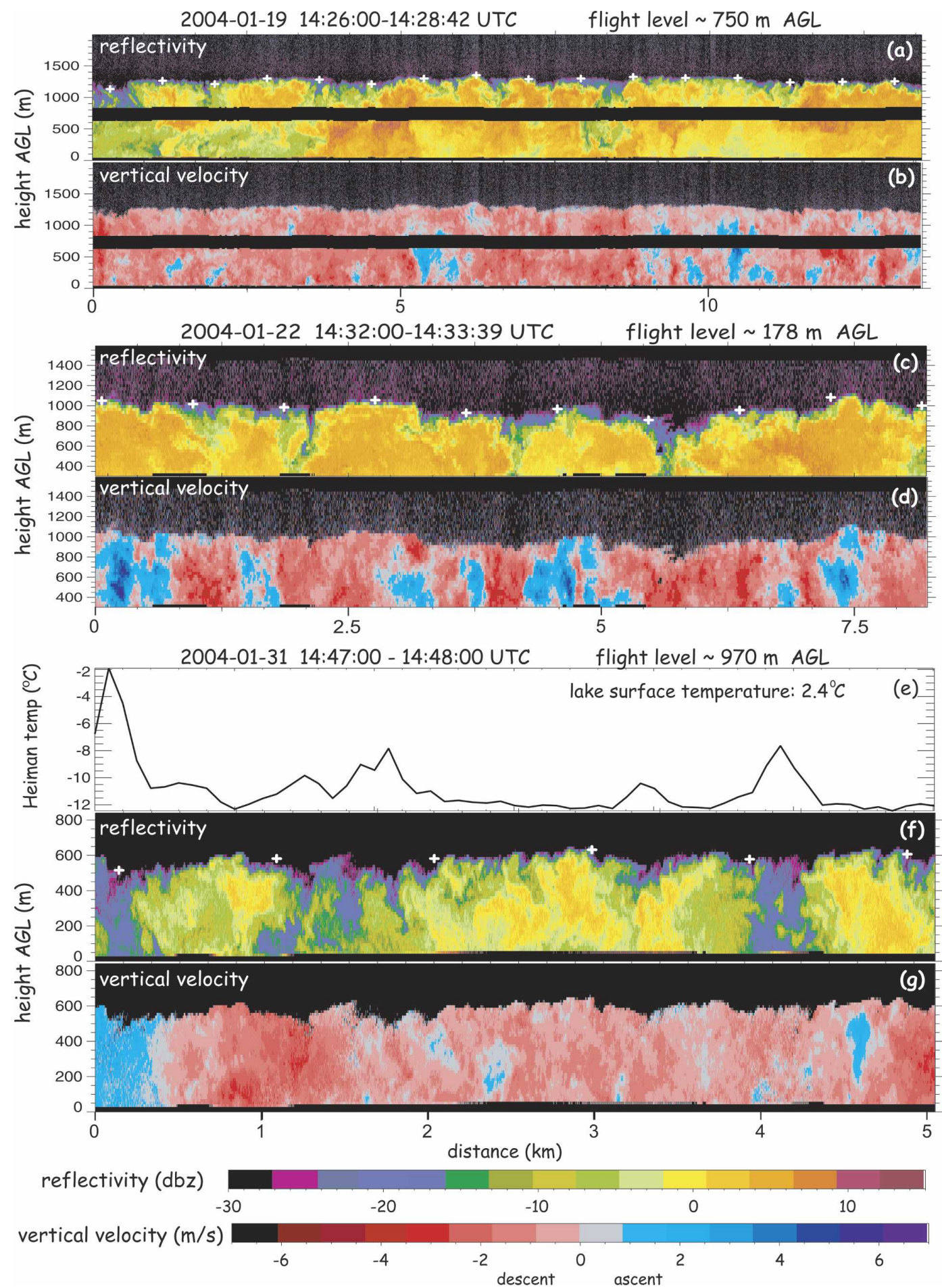

FIG. 5. Examples of (a), (c), (f) WCR reflectivity and (b), (d), (g) Doppler velocity from the 19, 22, and 31 January flights. The aspect ratio for each figure is 1:1. Positive vertical velocities represent upward particle motion. The white plus signs in (a), (c), (f) indicate the WCR-based CBL top $\left(z_{i-\text { WCR }}\right)$. Zenith and nadir radar beams are used in (a), (b); the black belt is the radar blind zone centered at flight level. The zenith beam is used in (c), (d), and the nadir beam is used in $(\mathrm{f}),(\mathrm{g})$. 

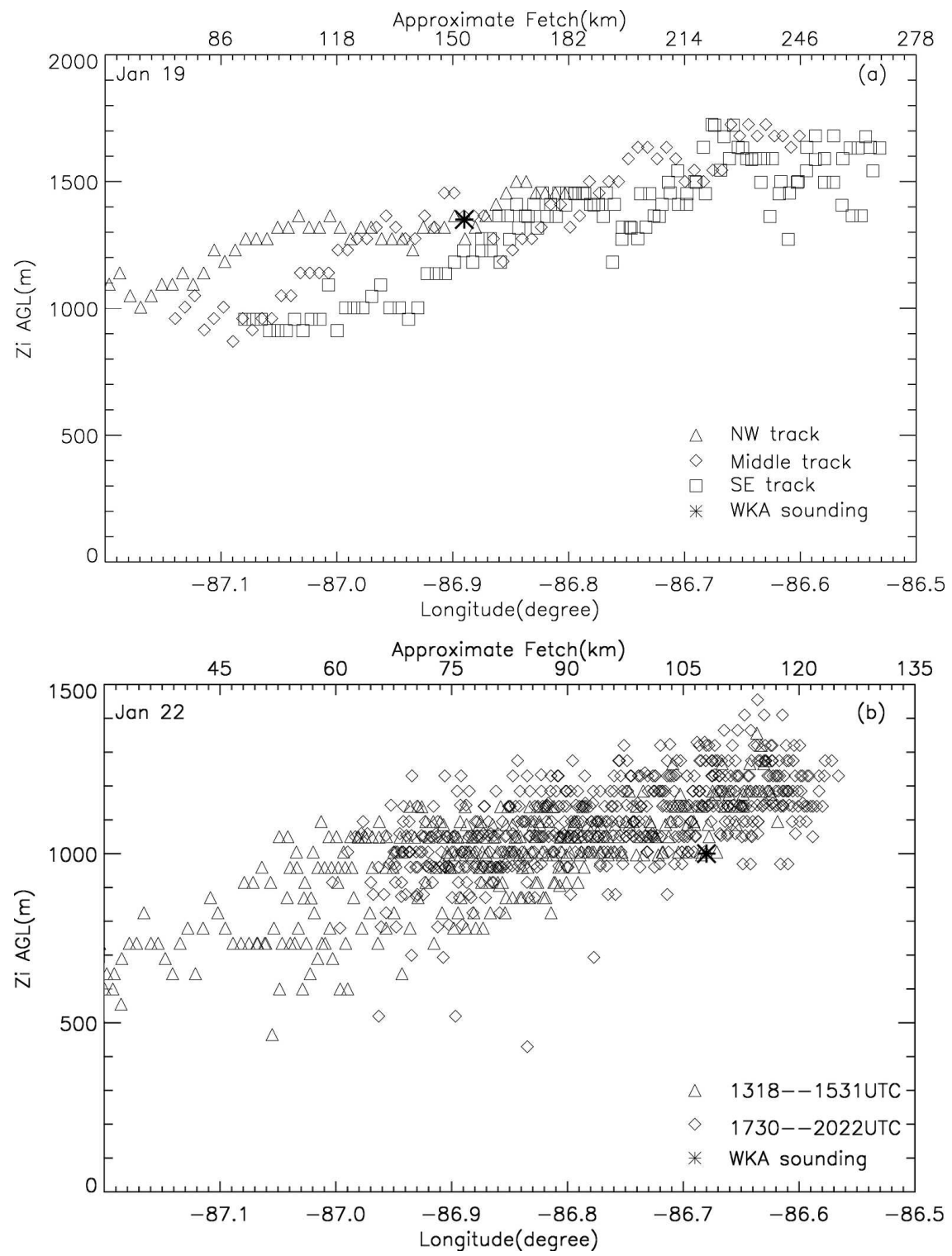

FIG. 6. The variation of CBL depth $z_{i}$ wCR with longitude and fetch from the upwind shore for several flight legs on (a) 19 and (b) 22 January. The fetch from the western shore of Lake Michigan (shown on the upper $x$ axis) is approximate because it is assumed that the wind direction is constant and the shore linear. The longitude (shown on the lower $x$ axis) is exact. Also shown, as a star, is the thermodynamically defined CBL depth $z_{i \mathrm{TH}}$ from WKA soundings (Figs. 4a,b). The three tracks (NW, middle, and SE) distinguished in (a) are shown in Fig. $1 \mathrm{~b}$. The two time periods distinguished in (b) are part of the morning and afternoon flights, respectively.

sience, or the time scale of convection, is an important one.

\section{c. Flow field in a vertical cross section across cloud streets}

A map of the wind field in the middle of the CBL, as shown in Fig. 3, does not directly reveal the secondary circulation that characterizes HCRs. A vertical transect across cloud streets does, as illustrated in Fig. 7. The mean flow in this transect is removed not only alongtrack but also in the vertical. The latter is intended to remove the fall speed component in the vertical motion of the scatterers. Thus the accuracy of the vertical velocity depends not only on factors related to platform motion and radar beam (Damiani and Haimov 2006), but also on the uniformity of the fall speed of the snow 


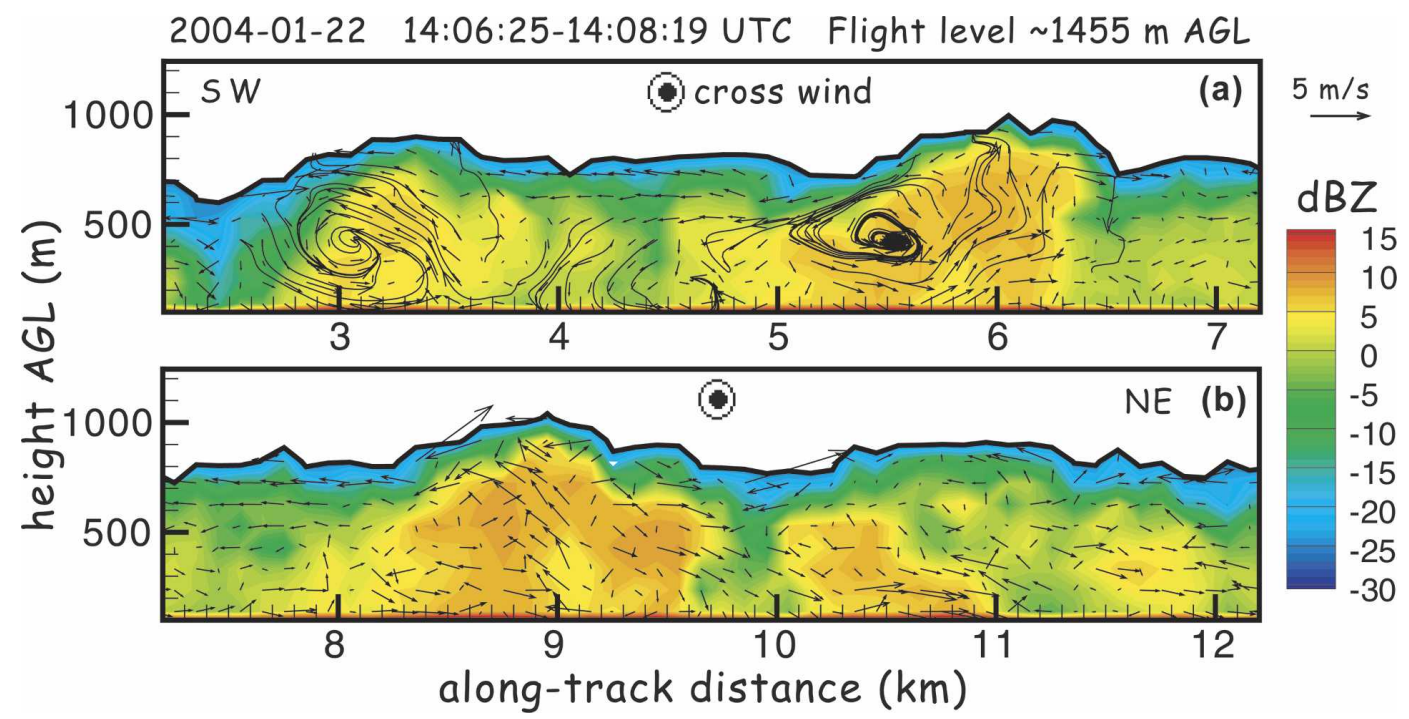

FIG. 7. Sample cross section of vertical-plane reflectivity and winds inferred from vertical-plane dual-Doppler synthesis below the aircraft. This section is along the western half of the middle track shown in Fig. 1d. The section is continuous but is cut in two to maintain a 1:1 aspect ratio. The prevailing wind blows out of the page. The dual-Doppler grid resolution is $100 \times 100 \mathrm{~m}^{2}$. The mean flow of $(-1.32,-0.20) \mathrm{m} \mathrm{s}^{-1}$ has been removed. The lines with arrows in (a) are select streamlines; i.e., they are tangential to the vectors.

crystals. The echo plumes in Fig. 7 are cloud streets intersected at near-normal angles $\left(\sim 22^{\circ}\right.$ clockwise of normal). The two strongest updraft plumes (near $x=$ $5.8 \mathrm{~km}$ and $x=9.1 \mathrm{~km}$ ) have a bounded weak-echo region. The $z_{i}$ above these plumes is at least $100 \mathrm{~m}$ above background $z_{i}$.

The streamlines in Fig. 7a highlight closed circulation cells with subsidence in the gaps, difluence at low levels, and confluence under the adjacent plumes. This provides rather strong evidence for a helical roll circulation. In concept, this circulation consists of counterrotating horizontal vortices-that is, the sign of the horizontal vorticity alternates-yet in Fig. 7 parallelrotating vortices with negative vorticity (pointing out of the page) dominate. This is due to ambient northeasterly shear (from right to left along the page, consistent with the Ekman spiral), which imparts negative vorticity in the CBL.

\section{Buoyancy and vertical velocity variations in the CBL}

We now describe the dynamical properties of CBL structures over Lake Michigan. A first and most obvious variable is the reflectivity within the CBL since the organization of convection commonly is described this way (e.g., Fig. 1). The strength of the airborne WCR observations lies in the synergy between radar data over the depth of the CBL and flight-level cloud, kinematic, and thermodynamic information.
A second approach lies in the vertical velocity field over the depth of the CBL. Dynamically, updraft "plumes" may be more relevant than echo plumes, since reflectivity is the result of a time integral of updrafts enabling ice particle growth, with the current time as upper bound of the integral. Thus updraft anomalies in the CBL are more likely to correspond with flight-level buoyancy than echo plumes. A third approach lies in the topography of the CBL: local domes in the CBL top, as inferred from the WCR zenith antenna, may correspond with a CBL updraft column (e.g., Fig. 7) and positive buoyancy.

It should be noted that the dynamical description of echo plumes, updrafts, or CBL domes presented herein does not distinguish between linear and cellular organization. Vertical profile radar data are used; that is, the horizontal organization is not explained. The key question addressed here is whether echo plumes (or updrafts or CBL domes) correspond with convective thermals.

\section{a. Dynamical characteristics of echo plumes}

\section{1) Vertical VARIATION OF REFLECTIVITY DISTRIBUTION}

We first quantify the variability of W-band radar reflectivity with height in the CBL. Shown in Fig. 8 are frequency-by-altitude diagrams (FAD) for three coldair outbreak events. Gap regions (i.e., between plumes) that were echo-free down to lake level were not en- 

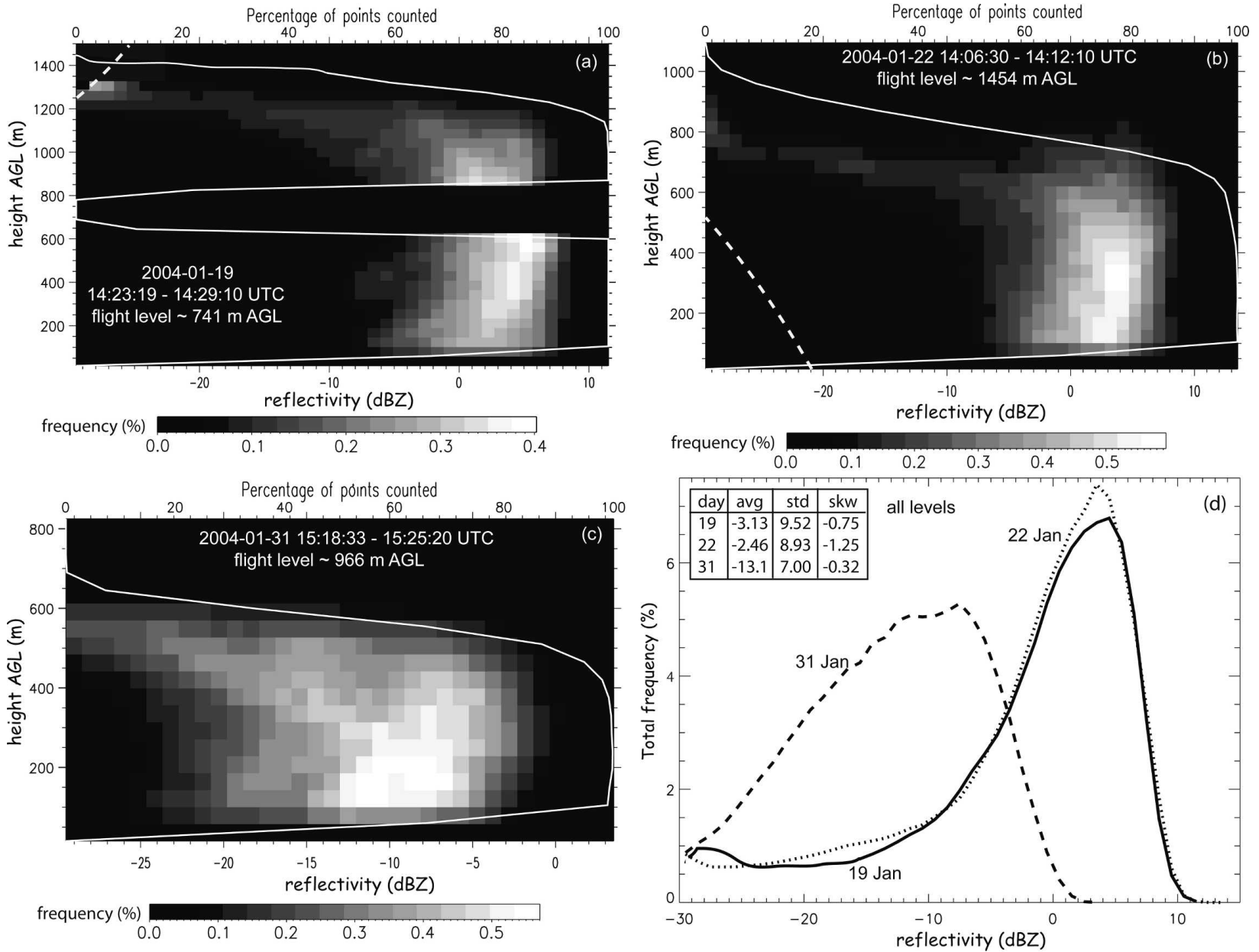

FIG. 8. (a)-(c) WCR reflectivity frequency-by-altitude diagram for select flight legs on three days. The boldface white line in (a)-(c) shows the percentage of pixels with measurable echoes at a given height, i.e., those with a return power above $-30 \mathrm{dBZ}$. The dashed white line in (a) and (b) shows the variation of the detection threshold with range. At a range of $1 \mathrm{~km}$, that is $-25.8 \mathrm{dBZ}$ for the zenith antenna and $-28.2 \mathrm{~dB} Z$ for the nadir antenna. No nadir antenna data collected above the CBL are available for 19 January, so up and down beams are combined, leaving a blind zone in the middle of (a). Some noise interferes with the signal near the CBL top on this day. (d) The distribution of reflectivity values from all heights for the flight legs on three days shown in (a)-(c). The average "avg" $(\mathrm{dBZ})$, standard deviation "std" (dBZ), and skewness "skw" (no dimensions) are listed for each day (19, 22, and 31 January) in (d).

countered on any of the three days. The gradual decrease in echo fraction ("percentage of points counted" in Fig. 8) near the CBL top is partly due to local $z_{i_{-} \text {WCR }}$ variations, partly to the variation of $z_{i_{-} \text {wCR }}$ with fetch (Fig. 6). The very low reflectivity values near the CBL top represent the gap regions, possibly entraining dry air from the free troposphere. The lack of weak echoes at low levels is not due to detection failure: the minimum detectable signal remains below the reflectivity distribution, even on 31 January.

The reflectivity distributions on the cloud street days are remarkably similar, and dissimilar from that on 31 January, when the average reflectivity is $\sim 10 \mathrm{dBZ}$ lower (Fig. 8d). The variation of reflectivity is rather small (Fig. 8d), but sufficient to visually identify plume and gap regions (Fig. 5). The distribution is negatively skewed at most levels. This is consistent with the crisper definition of gap compared to echo plumes, as is evident also in Figs. 2, 5, and 9. On 31 January (Fig. 8c) the distribution is broader and less skewed. A slight increase of median reflectivity with height is present on all days, up to $\sim 500 \mathrm{~m}$ ( $\sim 300 \mathrm{~m}$ on 31 January). The trend is believed to be due to sublimation below cloud base, which is higher on 19 and 22 January than on 31 January (section 4). The broadening of the reflectivity distribution just below the CBL top suggests that gap regions form from the top down and that the plumegap contrast is best defined in the upper CBL.

In short, the reflectivity FADs indicate that snow is relatively well mixed with height and horizontally, con- 


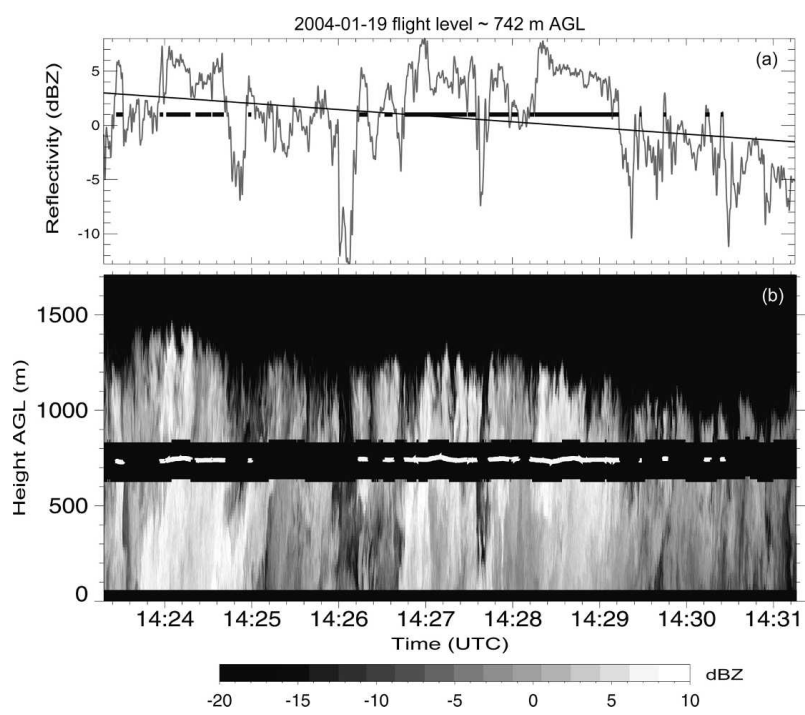

FIG. 9. (a) Trace of vertically averaged radar reflectivity $Z_{f}$ along the 1423:19-1431:15 UTC 19 Jan flight leg heading southwest. The thin black line is the trend line, and the bold short lines indicate echo plumes at a strength $\delta Z$ of $1 \mathrm{~dB} Z$, i.e., where $Z_{f}$ exceeds the trend line by at least $1 \mathrm{dBZ}$. (b) Corresponding radar reflectivity transect along this flight leg, plus the location of the same echo plumes, shown within the blind zone. The aspect ratio is about 10:1.

sistent with previous observations (e.g., Kristovich et al. 2003). This suggests that snow growth and decay are slow compared to the time scale of overturning by convection or HCRs.

\section{2) ECHO PLUME DEFINITION}

To quantitatively examine the characteristics of echo plumes, we apply a conditional sampling technique to echo plumes (Miao et al. 2006). The echo plume definition is based on vertically averaged radar reflectivity $(Z)$. The vertical average comprises 14 gates of radar reflectivity for each profile, that is, a depth of $180 \mathrm{~m}$. The averaging depth represents a compromise between capturing a sufficient depth and including enough profiles that have 14 gates of data located above the lake and below $z_{i \text { wCR }}$. Also, tilted plumes are broadened more as the averaging depth increases. Normally the first seven gates from the blind zone are used for both zenith and nadir beams, but for very low (high) flight levels in the CBL, all 14 gates come from the zenith (nadir) beam. A low-pass filter with cutoff wavelength of $100 \mathrm{~m}$ is used to filter out the finescale variability in $Z$, yielding $Z_{f}$. Since echo plumes tend to be stronger at the eastern end of a flight leg, $Z_{f}$ is linearly detrended, yielding $Z_{f d}$, whose flight-leg-mean value is defined as $Z_{m}$.

An echo plume is defined as a region (really only a

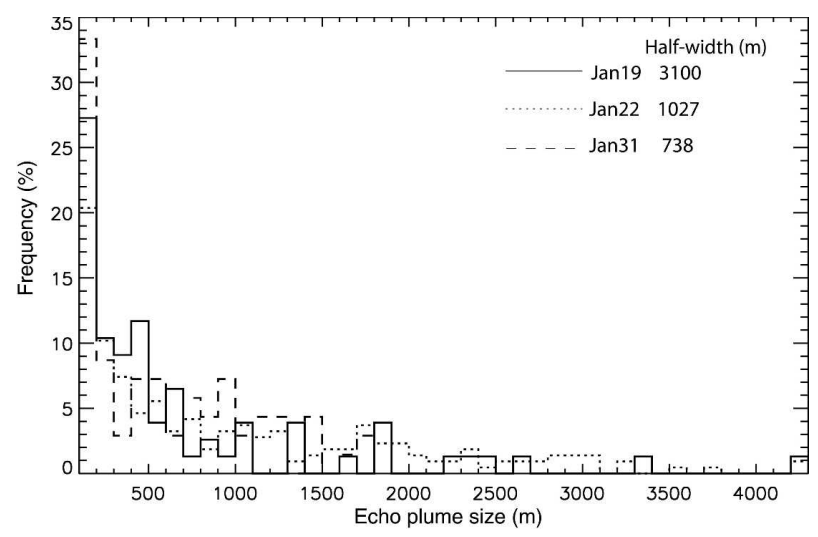

FIG. 10. Histograms of echo plume sizes for 19, 22, and 31 January. The assumed plume strength $\delta Z$ is $1 \mathrm{dBZ}$. In this case echo plumes occupy about $50 \%$ of the flight track. A $100-\mathrm{m}$ bin size is used. The four largest echo plumes (with sizes of 4.9, 6.0, 8.2 , and $8.6 \mathrm{~km}$, all observed on 19 Jan) are not shown.

line along the flight track) at least $100 \mathrm{~m}$ wide, where $Z_{f d} \geq Z_{m}+\delta Z(\delta Z \geq 0)$ (Fig. 9). A region with $Z_{f d}<$ $Z_{m}+\delta Z(\delta Z \geq 0)$ and at least $100 \mathrm{~m}$ wide is identified as background; $Z, Z_{f d}, Z_{m}$, and $\delta Z$ are all in units of $\mathrm{dB} Z$, yet all averaging occurs in native reflectivity units $\left(\mathrm{mm}^{6} \mathrm{~m}^{-3}\right)$.

Echo plumes thus defined come in a range of sizes. At $\delta Z=1 \mathrm{dBZ}$, the largest plume is $8.6 \mathrm{~km}$ wide, observed on 19 January. Radar imagery (Figs. 1 and 2) confirms the exceptional width of some echoes on 19 January. The size distribution decays roughly exponentially on all three days (Fig. 10); thus the distribution can be described in terms of the half-width of the bestfit exponential curve, equivalent to the half-life of radioactive isotopes. Plumes are generally smaller on the day without rolls.

\section{3) ECHO PLUME DYNAMICAL PROPERTIES}

To assess whether echo plumes tend to be buoyant, we compute the virtual potential temperature $\theta_{v}$, which in our definition includes effect of hydrometeor loading on buoyancy (Houze 1993, p. 36; Stull 1988, p. 7):

$$
\theta_{v}=\theta\left(1+0.61 q-q_{H}\right),
$$

where $q_{H}$ is the hydrometeor mixing ratio. Horizontal variations from the long-track-mean $\theta_{v}$ are linearly proportional to the buoyancy force, at least if pressure perturbations are ignored. The mixing ratio $q$ is inferred from an open path water vapor absorption band probe (LICOR). The temperature is detected by a reverse flow thermometer. The term $q_{H}$ is the sum of the liquid water content (LWC: measured by a hot-wire probe) and the mixing ratios of snow particles of vari- 
ous sizes as measured by the 2D-P and 2D-C particle probes. For each flight leg examined here, the average LWC $<0.1 \mathrm{~g} \mathrm{~kg}^{-1}$ on all three days, and the peak 100 -m values $<0.2 \mathrm{~g} \mathrm{~kg}^{-1}$, thus the (negative) contribution of LWC to buoyancy, is very small. More significant is the snow mixing ratio, which averages $0.6 \mathrm{~g}$ $\mathrm{kg}^{-1}$ for the 19-22 January flight legs examined here, and $0.2 \mathrm{~g} \mathrm{~kg}^{-1}$ for 31 January.

We examine the anomalies of specific humidity, potential temperature, and virtual potential temperature $\left(q^{\prime}, \theta^{\prime}, \theta_{v}^{\prime}\right)$ and also gust probe vertical air motion $w$ within echo plumes of various strengths (Fig. 11). The anomalies are defined as differences between plume and background values. Two low-level flight legs and two midlevel legs are used for 19 January, four lowlevel legs and six midlevel legs for 22 January, and three low-level legs for 31 January. No upper CBL flight legs are used because they intersect $z_{i}$ as $z_{i}$ slopes down toward the west (Fig. 6). In the vicinity of this intersection a strong signal encountered across an undulating CBL top, due to alternating sampling of the warmer free troposphere and the more humid CBL air: for such flight legs echo plumes (as well as updraft plumes and CBL domes, discussed below) are negatively buoyant, irrespective of the forcing mechanism (Grossman 1984).

Four values of plume strength $\delta Z$ are used: clearly the more restrictive the definition of an echo plume, the stronger the signal should be, but, on the other hand, the fraction of profiles in echo plumes (Fig. 11e) becomes smaller and thus the statistical significance of the plume properties weaker. The highest plume strength $(\delta Z=3)$ is chosen such that all flight legs have at least three plumes. The same criterion will be used for updraft plumes and echo domes, below.

Mixing ratio anomalies are generally positive (0.02$0.15 \mathrm{~g} \mathrm{~kg}^{-1}$ ) and rather independent of plume strength (Fig. 11a). The plume $\theta$ anomalies are generally positive on 22 and 31 January, but negative on 19 January. The hydrometeor loading term in plumes (not shown) is a small negative contribution to the virtual potential temperature for all flight legs. The net effect of the three terms on $\theta_{v}$ anomalies in echo plumes is negative for the three 19 January flight legs $\left(\theta_{v}^{\prime} \approx-0.3 \mathrm{~K}\right)$ as well as for three midlevel flight legs on 22 January $\left(\theta_{v}^{\prime} \approx\right.$ $-0.1 \mathrm{~K}$ ), and near-zero for the remaining flight legs. Generally low-level flight legs are slightly more buoyant than midlevel ones. No clear dependence on plume strength is evident. Plumes recorded on the day without rolls (31 January) tend to be slightly positively buoyant $\left(\theta_{v}^{\prime}<0.1 \mathrm{~K}\right)$, but this characteristic does not clearly separate the no-roll plumes from plumes on a day with rolls (22 January).
Notwithstanding the lack of buoyancy, most echo plumes experienced rising motion relative to the background (Fig. 11d). The ascent is more pronounced for midlevel flight legs. Sinking motion prevails in plumes on the three 19 January flight legs that tend to have negatively buoyant echo plumes.

\section{b. Dynamical characteristics of updrafts}

\section{1) Vertical VARIATION of VerTiCAl VELOCITY DISTRIBUTION}

Inspired by the observed lack of buoyancy in radar echoes in the CBL, both on two days with rolls and a day without rolls, we examine the WCR vertical velocity pattern and relate updrafts to buoyancy. Downward particle motion clearly prevails on all three days (Fig. 5) due to the terminal velocity of snow crystals. Updrafts seem to be narrower than echo plumes, for example, on 22 January (Figs. 5c and 5d). Most updrafts correspond with higher reflectivity, and, in fact, echo plumes tend to experience rising motion (Fig. 11d), but some echo plumes are subsident.

Vertical velocity FADs for three cold-air outbreaks are shown in Fig. 12. The mean rate of subsidence ranges from 0.67 to $0.98 \mathrm{~m} \mathrm{~s}^{-1}$. Analysis of PMS 2D-P images indicates little riming on the snow crystals. This is consistent with the low supercooled LWC (observed also in previous studies; e.g., Kelly 1982) and with the temperature range near $-14^{\circ} \mathrm{C}$ (Fig. 4), which is optimal for crystal growth by deposition. The LWC along the highest in-cloud flight leg averages $0.06,0.04$, and $0.01 \mathrm{~g} \mathrm{~kg}^{-1}$ on 19, 22, and 31 January, respectively. The fall speed of unrimed snow at $\sim 950 \mathrm{mb}$ is about 1.0 $\mathrm{m} \mathrm{s}^{-1}$, varying little with crystal habit and increasing only slightly with size and thus with reflectivity (Locatelli and Hobbs 1974). This figure agrees well with the observed mean rate of subsidence.

As a first guess, rising (sinking) air occurs for pixels to the right (left) of the dashed line in Figs. 12a-c. Subsidence is more common than ascent (i.e., the updrafts are smaller), but the updrafts are stronger, on all three days. This positive skewness of the vertical air velocity distribution is most prominent on the day with weak winds and no rolls (Fig. 12d). It is a general property of a CBL (Young 1988; LeMone 1990), including the CBL that develops when cold air flows over warmer water (Agee and Hart 1990; Rao and Agee 1996), but it is not a property of purely helical flow.

In contrast, the reflectivity FADs (Fig. 8) indicate a negative skewness, that is, an areal predominance of echo plumes (section 5a). The implications are that some echo plumes must contain downdrafts and that updraft plumes are narrower and more crisply defined 
anomalies in echo plumes
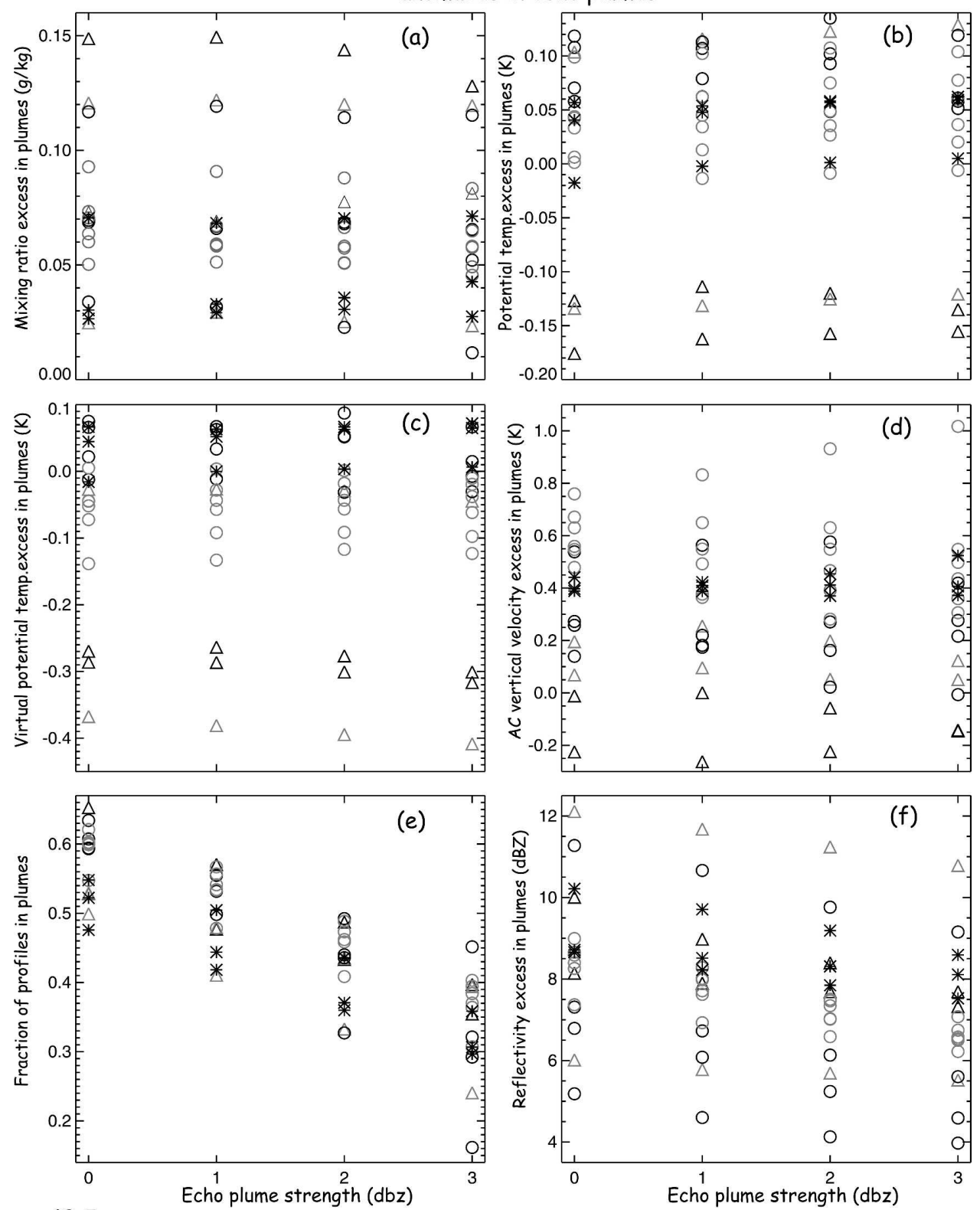

\section{$\triangle 19 \mathrm{Jan}$ \\ - 22 Jan grey: mid-level \\ * 31 Jan black: low-level}

FIG. 11. Leg-mean anomalies of (a) $q$, (b) $\theta$, (c) $\theta_{v}$, and (d) $w$ in echo plumes, for various flight legs on three days, as a function of echo plume strength $(\delta Z)$. Each symbol represents one flight leg. Also shown are (e) the fraction of the flight track considered to be in-plume, i.e., the number of profiles in echo plumes divided by the total number of profiles along a flight leg (background + plume), and (f) the mean reflectivity excess in echo plumes. The results are stratified by day and by flight level: "low-level" flight legs are below $0.3 z_{i_{-} \mathrm{WCR}}$ and midlevel legs are between 0.3 and $0.7 z_{i_{-} \mathrm{WCR}}$.

than echo plumes. The correlation coefficients between reflectivity and WCR vertical velocity in the closest 14 range gates, for the flight legs studied here, range between 0.31 and 0.71 for 31 January, 0.26 and 0.68 for 22 January, and 0.04 and 0.29 for 19 January.
The range of velocities confirms the convective nature of the BL (Houze 1997), as does the structure of echoes and updrafts in the transects in Fig. 5. For instance, on 22 January a series of narrow updraft towers can be seen, with rising air motion strong enough to lift 

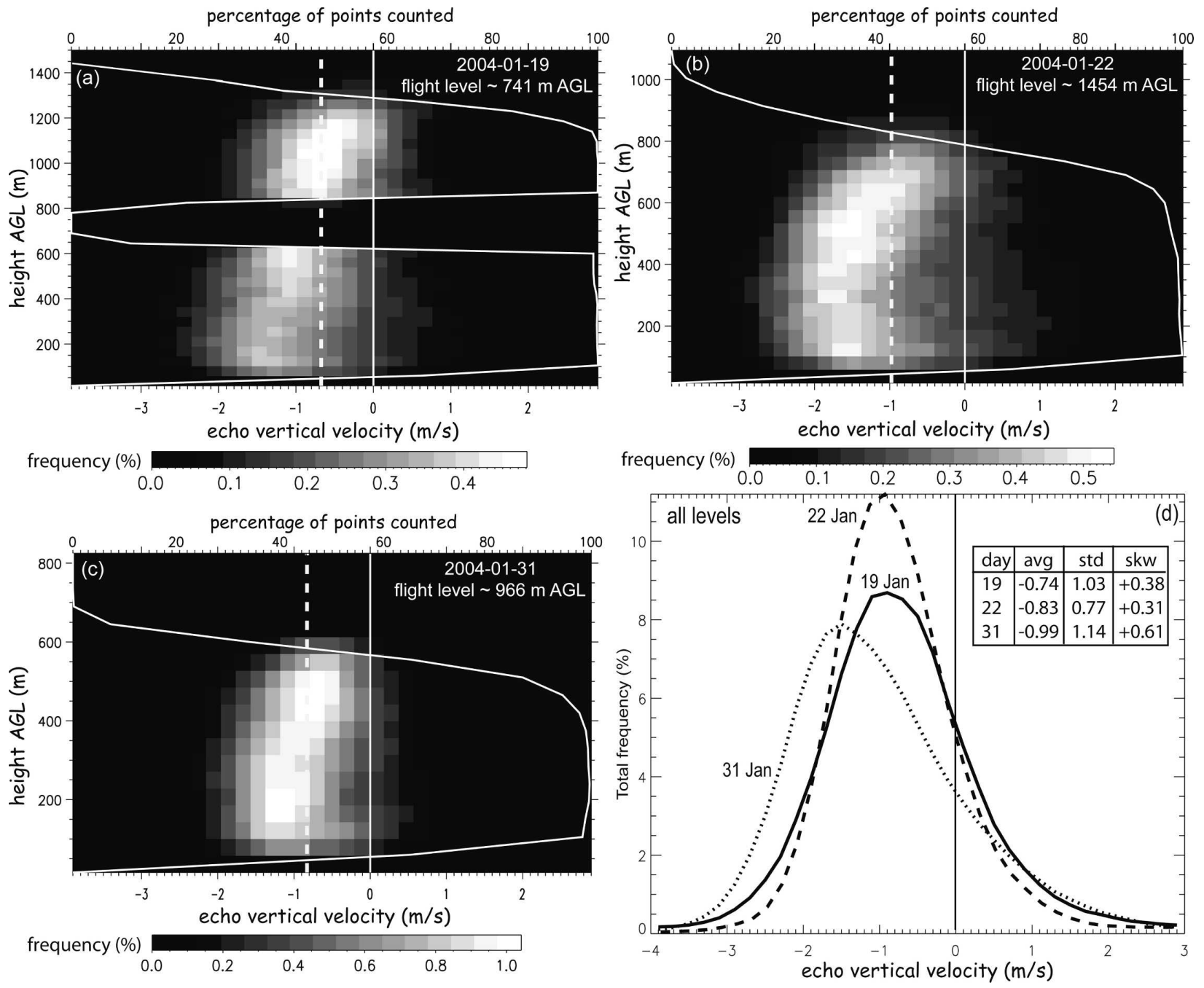

FIG. 12. As in Fig. 8 but for vertical velocity. The dashed white line in (a)-(c) is the mean vertical velocity. (d) The average "avg" and standard deviation "std" have units of $\mathrm{m} \mathrm{s}^{-1}$.

snow at up to $3 \mathrm{~m} \mathrm{~s}^{-1}$. The velocity range is largest in the lower CBL (Figs. 12a-c); thus updraft plumes are best defined there. Finally, the mean particle vertical motion tends to increase with height in the CBL, on all days. This may be due to preferred sampling of the deeper echo plumes, where rising motion is more likely, at least in the upper CBL.

\section{2) UPDRAFT PLUME DEFINITION}

We define updraft plumes analogously to echo plumes [section 5a(2)]. The focus now is on WCRdetected updrafts over a substantial part of the CBL depth. The WCR vertical velocity is averaged over a depth of 14 gates in proximity of the aircraft. This value $(V)$ is low-pass filtered $\left(V_{f}\right)$, allowing wavelengths of $100 \mathrm{~m}$ or more, and detrended $\left(V_{f d}\right)$. The leg-mean $V$ is denoted as $V_{m}$. A region with $V_{f d} \geq V_{m}+\delta V(\delta V \geq 0)$ and at least $100 \mathrm{~m}$ wide is called an updraft plume. Regions at least $100 \mathrm{~m}$ wide with $V_{f d}<V m+\delta V$ constitute the background. The updraft strength $\delta V$ is chosen to range between 0 and $1 \mathrm{~m} \mathrm{~s}^{-1}$. The average fraction of profiles in updraft plumes is only $12 \%$ at the upper limit $\left(\delta V=1 \mathrm{~m} \mathrm{~s}^{-1}\right)$, but each flight leg still has sufficient plumes. Note that $\delta V$ is a differential quantity, that is, an excess above the mean. An example of this updraft plume definition is shown in Fig. 13.

Updraft plumes (Fig. 14) are smaller than echo plumes (Fig. 10), as suggested by observations (Fig. 5). The smallest bin size $(100 \mathrm{~m})$ dominates. The sizes do decay roughly exponentially, as for echo plumes, and as observed using gust probe vertical velocity in the continental CBL (Young 1988), at least for sizes exceeding $\sim 100 \mathrm{~m}$. The half-widths of updraft plumes are an order of magnitude smaller than those of echo plumes, and 


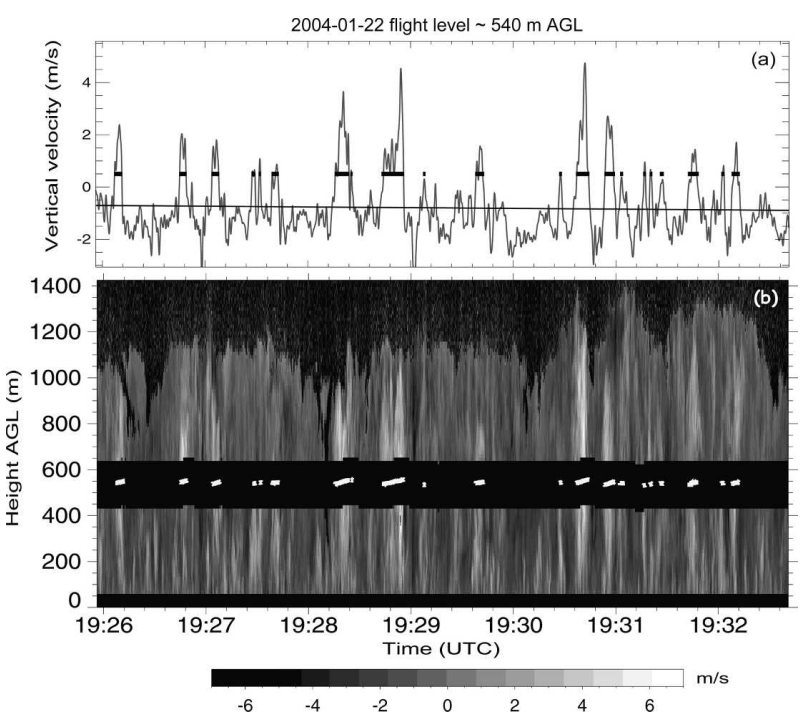

FIG. 13. As in Fig. 9 but for WCR vertical velocity $\left(V_{f}\right)$, for a NE-bound flight leg between 1925:56 and 1932:41 UTC 22 Jan. The updraft strength $\delta V$ that defines the updraft plumes is 0.5 $\mathrm{m} \mathrm{s}^{-1}$.

also those of the downdraft-dominated "background" regions. For the day without rolls (31 January), the halfwidth is smaller than that for the two cloud street days, as for echo plumes (Fig. 10). Clearly the linear organization of convection tends to yield broader updrafts.

\section{3) UPDRAFT PLUME DYNAMICAL PROPERTIES}

The same variables used in Fig. 11 are now examined in updraft plumes, using the same flight legs, for various updraft strengths (Fig. 15). Both $q^{\prime}$ and $\theta^{\prime}$ are positive in updraft plumes, and their magnitude generally increases with increasing updraft strength. The average $q$ and $\theta$ anomalies are $0.02 \mathrm{~g} \mathrm{~kg}^{-1}$ and $0.10 \mathrm{~K}$ larger than the corresponding values in echo plumes. The reflectivity anomaly in the 14 matching gates (Fig. 15f) is positive on 31 January, but negative on 19 January. This is consistent with Fig. 11d (where gust probe vertical velocity is assessed). As a result the hydrometeor loading term in the buoyancy equation (1) can have either sign within updraft plumes (negative on 31 January and positive on 19 January), but it is smaller than the $\theta$ term.

The buoyancy $\theta_{v}^{\prime}$ in updraft plumes is positive in most cases (Fig. 15c) and larger in stronger updraft plumes. The buoyancy tends to be larger for low-level flights, but the gust probe vertical velocity in updraft plumes (Fig. 15d) is larger at mid levels than at low levels in the CBL. All this is dynamically consistent, as it follows from the one-dimensional steady-state entraining jet model (e.g., Squires and Turner 1962).

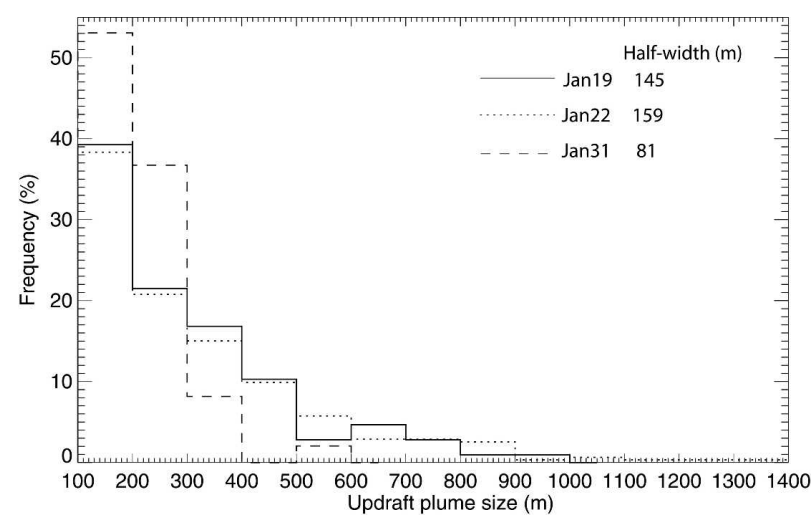

FIG. 14. As in Fig. 10 but for updraft plumes. The updraft strength $\delta V$ is $0.5 \mathrm{~m} \mathrm{~s}^{-1}$, which implies that updraft plumes cover $21 \%$ of the combined track of all flight legs.

We conclude that updraft plumes (below $0.7 z_{i}$ ) tend to be positively buoyant and thus embody BL thermals, as has been shown by other observational CBL studies (e.g., Greenhut and Khalsa 1982; Young 1988). The day lacking linear echo organization (31 January) has weaker updrafts (Fig. 15d), and strong updraft plumes are less common (Figs. 15e and 12). These updrafts are narrower (Fig. 14), their buoyancy is slightly less (Fig. $15 \mathrm{c})$, and they more clearly coincide with echo plumes (Fig. 15f) compared to the two days with rolls. The interpretation is that on 31 January, smaller and weaker convective updrafts occur, producing less supercooled LW; snow crystals are less likely to be ejected on top; that is, they have a longer residence time in the updraft.

\section{c. Dynamical characteristics of $C B L$ domes}

\section{1) CBL DOME DEFINITION}

We now explore whether ridges (in case of 2D organization) or more generally "domes" in the CBL top are sustained by buoyancy-driven updrafts in the CBL. WCR zenith-antenna reflectivity profiles are used to determine the CBL top $z_{i-\mathrm{wCR}}$. The distribution of $z_{i-}$ -wCR has been documented (Fig. 6). In Figs. 5 and 6, $z_{i \text { WCR }}$ is based on $10-\mathrm{s}(\sim 800 \mathrm{~m})$ intervals. For the purpose of exploring the dynamical properties of CBL domes, we compute $z_{i \_ \text {WCR }}$ every $100 \mathrm{~m}$ along the flight track. This resolution implies $\sim 45$ reflectivity profiles per $z_{i \_ \text {wCR }}$ estimate, which is sometimes inadequate for gap regions, but proves to work well for echo plumes where the CBL domes tend to occur.

The method used for echo plumes and updraft plumes is used here. The 100-m $z_{i_{-} \text {WCR }}(H)$ is detrended $\left(H_{d}\right)$. The leg-mean $H$ is denoted as $H_{m}$. A region with $H_{d} \geq H_{m}+\delta H$ is a CBL dome, while the rest is background. The maximum dome strength $\delta H$ 

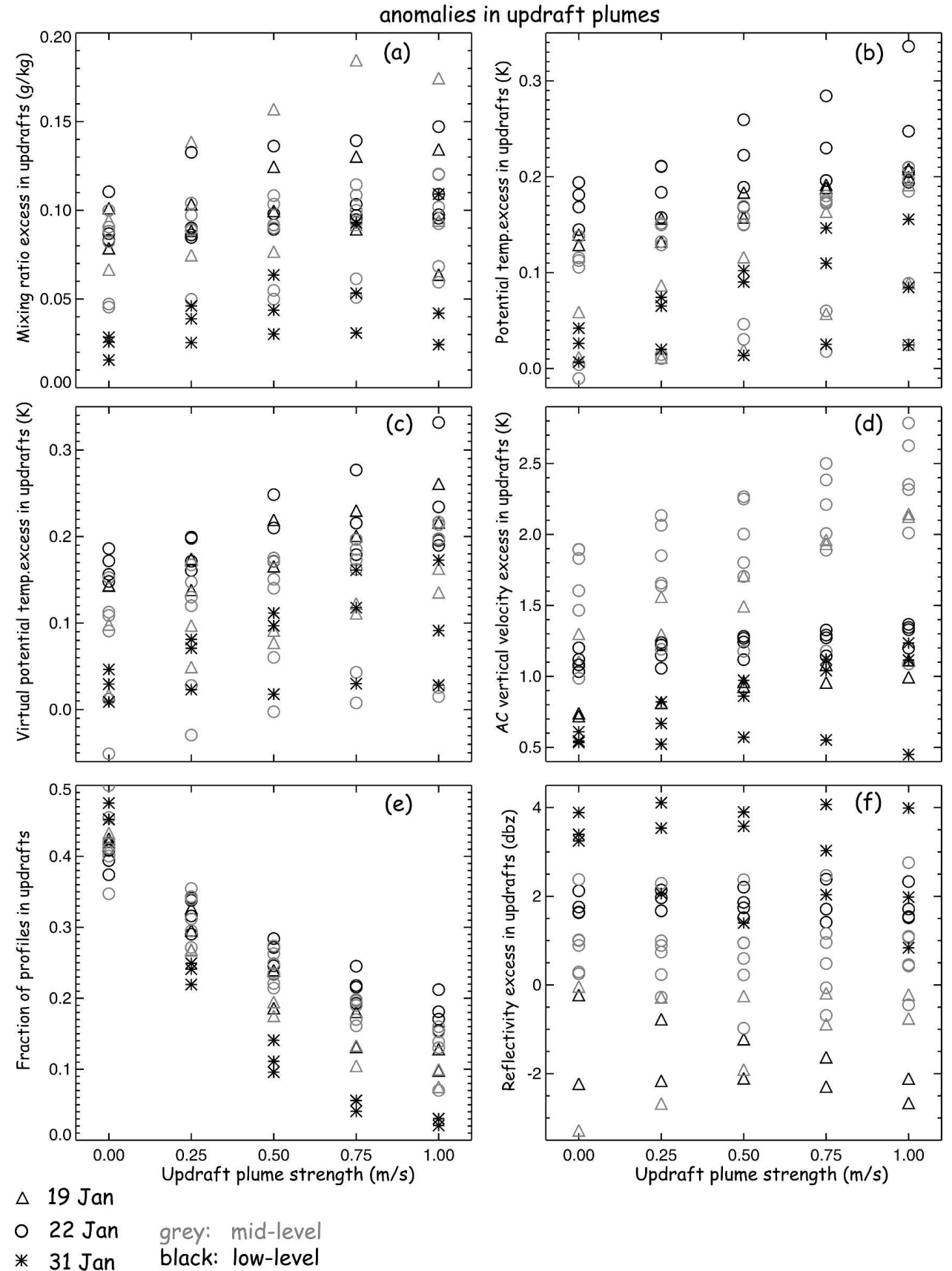

FIG. 15. As in Fig. 11 but for updraft plumes.

selected, $90 \mathrm{~m}$, is again based on the number of domes remaining. At $\delta H=90 \mathrm{~m}$, domes represent $15 \%$ of the profiles.

CBL domes are typically smaller than echo plumes, but larger than updraft plumes (Fig. 16). Their size distribution also can be presented well by means of an exponential curve: the smallest bin $(100 \mathrm{~m})$ is the most common. The CBL domes on 31 January (no rolls) are smaller than those on the two days with rolls, and their size distribution matches that of the 31 January updraft plumes. The domes are also far less pronounced on 31 January, that is, the CBL topography is smoother: fewer domes are found at any height threshold (30$90 \mathrm{~m}$ ) compared to 19 and 22 January (Fig. 17e).

\section{2) CBL DOME DYNAMICAL PROPERTIES}

CBL domes correspond with higher-than-normal reflectivity in the CBL for all flight legs (Fig. 17f). The 


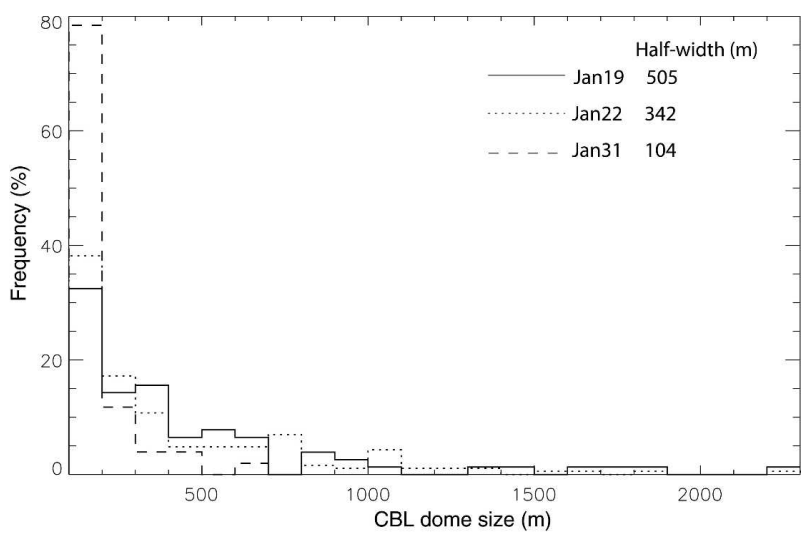

FIG. 16. As in Fig. 10 but for $\mathrm{CBL}$ domes. The $\mathrm{CBL}$ dome strength $\delta H$ is $30 \mathrm{~m}$, which implies that CBL domes occupy $36 \%$ of the combined flight track.

correlation between CBL height $z_{i \text { WCR }}$ and reflectivity within the CBL is higher than the correlation between WCR vertical velocity and reflectivity. On 19 and 22 January, CBL domes are supported by updrafts underneath, especially at mid levels (Fig. 17d). The $q$ anomalies in CBL domes are about the same as in echo plumes (Fig. 17a), with larger values on 19 January and near-zero values on 31 January, and little dependence on the strength of the CBL dome. Average $\theta$ anomalies are slightly $(0.05 \mathrm{~K})$ larger than those in echo plumes (Fig. 17b). The negative anomalies found in 19 January echo plumes (Fig. 11b) are absent except for two legs at low CBL dome threshold. The hydrometeor loading term contributes negatively to the buoyancy for all legs, as can be inferred from its proxy, reflectivity (Fig. 17f).

For some flight legs the echo dome "roots" (i.e., the region vertically below the echo dome) tend to be buoyant; for others they are not (Fig. 17c). The mean value of $\theta_{v}^{\prime}$ for all flight legs is near zero. The variance amongst these legs is larger than the mean. Negative buoyancy is encountered on certain flight legs on any of the three days, and both for low-level and midlevel flight legs. On January 19 echo dome root buoyancy is higher than echo plume buoyancy, but still mostly negative. On average, echo domes along the 22 January flight legs have more buoyant roots than on the two other days, and thus updrafts tend to be stronger there (Fig. 17d), although not as strong as in updraft plumes.

\section{Discussion}

Echo cells of convective origin should have a lowlevel buoyant core and a midlevel updraft (e.g., Squires and Turner 1962), at least early on in their life cycle, irrespective of whether they are organized in cellular or linear patterns. We found it difficult to assess the convective nature from thermodynamic properties: echo plumes were found to be neutrally buoyant, on average, containing mostly updrafts but also some downdrafts. This may be because the life cycle of a snow shower (i.e., echo plume) includes the decaying stage of convection. Given the low cloud base and near-optimal temperature range for depositional growth of ice crystals, the decaying phase may bear a higher reflectivity than the growing phase. The fact that echo plumes are of variable buoyancy and do not clearly coincide with updraft plumes testifies to the short life of convective ascent. The updrafts carry snow to the upper CBL and disperse it there, causing the echo plumes to be larger than the updrafts. Echo plumes may well be the result of multiple thermals. The small size of gaps (as evident, e.g., in Figs. 5c and 9) implies that the "background" comprises a minority of the CBL and thus in-plume $\theta_{v}^{\prime}$ does not match the conceptual image of a local perturbation embedded in an infinitely large, hydrostatically balanced background field. It might have been more appropriate to study the (negative) buoyancy of gaps instead. This cautionary remark does not apply to updraft plumes, which are much smaller (Fig. 14), and it applies less as the echo plume strength $\delta Z$ increases.

$\mathrm{CBL}$ domes (or ridges) are generally associated with higher reflectivity and updrafts below, more so at mid levels than at low levels. But we found, at best, only weak evidence for buoyantly driven variations in the CBL topography. The same life cycle problem as for echo plumes may affect our findings: the domes (or ridges) may be the result of past buoyancy. Buoyancy is complex, since it as affected both by variations in surface heat flux and by latent heat release in updrafts, but certainly it drives vertical accelerations (the integration of which yields vertical velocity). Both particle sizes (i.e., reflectivity) and overshoot depth (i.e., CBL domes) in turn are a time integral of vertical velocity. It is not surprising, then, that updraft plumes are clearly buoyant, as has been observed elsewhere (Braham and Kristovich 1996). Echo plumes and CBL domes appear to carry too much history to relate well to instantaneous buoyancy. It would be more productive to relate local rate of change of reflectivity or CBL topography to in situ buoyancy estimates, but unfortunately we only have single snapshots in time.

Certainly the horizontal and vertical view of echoes and updrafts gives the impression that the BL studied here is convectively driven, although in the case of cloud streets the horizontal and vertical flow fields clearly are modulated by the HCR circulation. The only clear difference on 31 January (the day lacking linear echo organization) is that the CBL on that day has 
anomalies in CBL domes
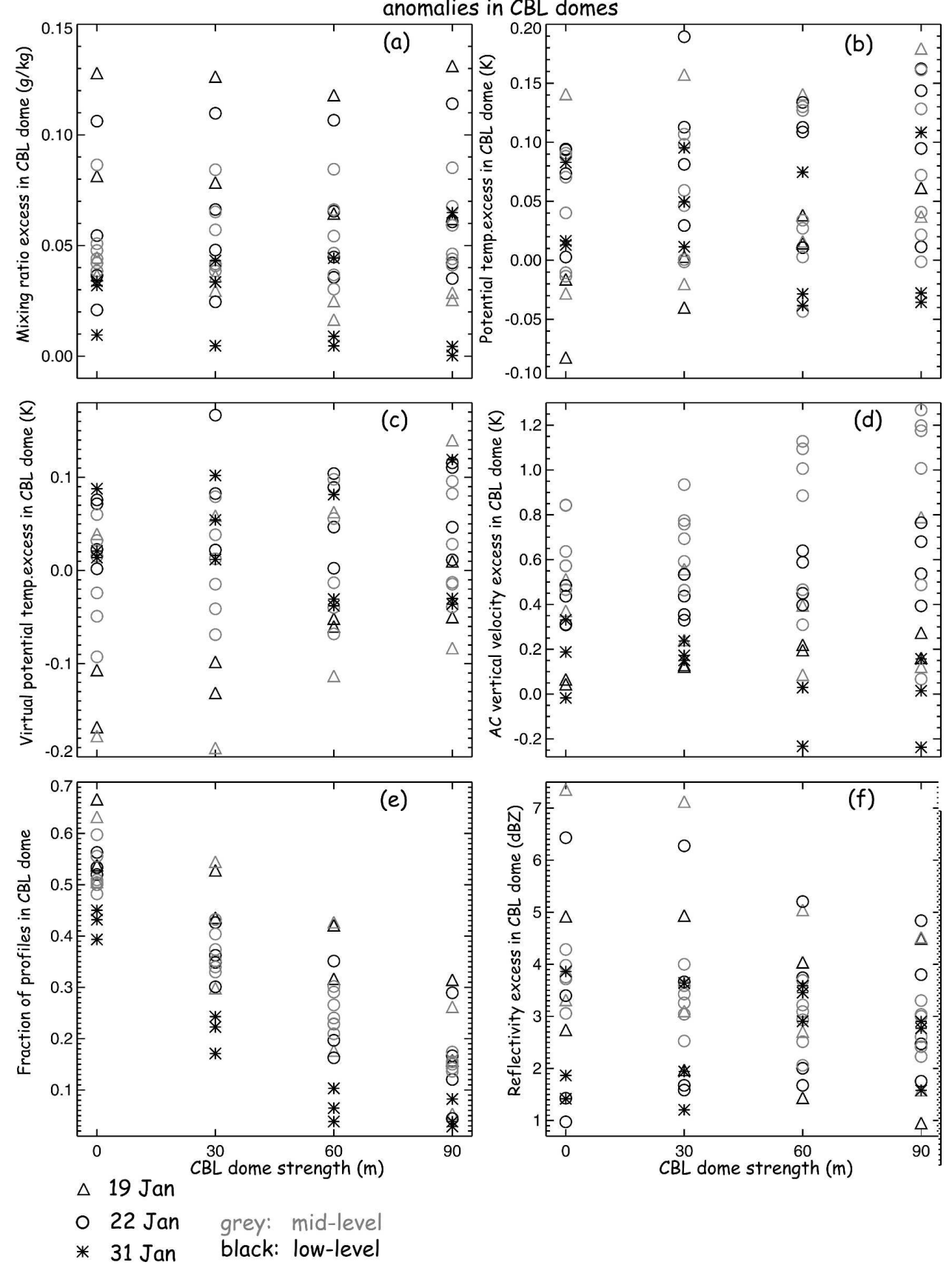

FIG. 17. As in Fig. 11 but for CBL domes.

weaker, narrower, and less buoyant updrafts that disturb the CBL top less and that coincide better with echo plumes, compared with the two days with rolls, probably because the wind is weaker and the surface heat flux lower on this day. But the difference between the two days with rolls is large. The unusually wide cloud streets on 19 January may have been affected by mesoscale processes induced by the land surface east of
Lake Michigan since the CBL wind was oriented nearly along the length of the lake (e.g., Agee and Hart 1990).

\section{Conclusions}

Aircraft and airborne cloud radar data are used to describe the kinematic and dynamic structure of the CBL during three cold-air outbreak events over Lake 
Michigan. Two of them had cloud streets, one with a typical aspect ratio and one with an unusually large aspect ratio. The dual-Doppler flow field in a vertical transect provides unambiguous evidence for horizontal convective rolls on the day with a typical aspect ratio. The wind speed and CBL depth on the day without cloud streets was only $\sim 50 \%$ of that on the other days, and convective updrafts were weaker and narrower, yet the air mass modification was larger over the same fetch.

Convective activity within the CBL is marked by means of three independent radar-inferred variables, namely echo plumes, updraft plumes, and CBL domes. Echo plumes are much wider than updraft plumes, and CBL domes are of intermediate size. Only updraft plumes have the characteristics of buoyant, entraining thermals. The lack of a clear buoyancy signal in echo plumes and CBL domes is attributed to a phase shift between peak buoyancy, peak updraft speed, and peak overshooting (i.e., CBL dome size) or peak snow size (i.e., reflectivity), and is evidence for the relatively short lifespan of buoyant thermals, even on days with horizontal convective rolls.

Acknowledgments. This research was supported by National Aeronautics and Space Administration Grant EPSCoR3412. Dave Leon processed the WCR radial velocities. Sarah Walters provided the results of the spectral analysis of flight-level data for the 22 January flights. Rick Damiani provided the tools to analyze WCR Doppler velocities, and Qun Miao built the WCR-based conditional sampling software. This work greatly benefited from the comments of Ralph Foster, Margaret LeMone, and Tammy Weckwerth.

\section{REFERENCES}

Agee, E. M., and M. L. Hart, 1990: Boundary layer and mesoscale structure over Lake Michigan during a wintertime cold air outbreak. J. Atmos. Sci., 47, 2293-2316.

Asai, T., 1972: Thermal instability of shear flow turning the direction with height. J. Meteor. Soc. Japan, 50, 525-532.

Atkinson, B. W., and J. W. Zhang, 1996: Mesoscale shallow convection in the atmosphere. Rev. Geophys., 34, 403-431.

Braham, R. R., Jr., and D. A. R. Kristovich, 1996: On calculating the buoyancy of cores in a convective boundary layer. J. Atmos. Sci., 53, 654-658.

Brooks, I. M., and D. P. Rogers, 1997: Aircraft observations of boundary layer rolls off the coast of California. J. Atmos. Sci., 54, 1834-1849.

Brown, R. A., 1972: On the inflection point instability of the stratified Ekman boundary layer. J. Atmos. Sci., 29, 850-859.

_ 1980: Longitudinal instabilities and secondary flows in the planetary boundary layer: A review. Rev. Geophys. Space Phys., 18, 683-697.

Chlond, A., 1992: Three-dimensional simulation of cloud street development during a cold-air outbreak. Bound.-Layer Meteor., 58, 161-200.

Christian, T. W., and R. M. Wakimoto, 1989: The relationship between radar reflectivities and clouds associated with horizontal roll convection on 8 August 1982. Mon. Wea. Rev., 117, $1530-1544$.

Damiani, R., and S. Haimov, 2006: A high-resolution dualDoppler technique for fixed multi-antenna airborne radar. IEEE Trans. Geosci. Remote Sens., in press.

Etling, D., and R. A. Brown, 1993: Roll vortices in the planetary boundary layer: A review. Bound.-Layer Meteor., 65, 215-248.

Foster, R. C., 2005: Why rolls are prevalent in the hurricane boundary layer. J. Atmos. Sci., 62, 2647-2661.

Geerts, B., and Q. Miao, 2005: The use of millimeter Doppler radar echoes to estimate vertical air velocities in the fairweather convective boundary layer. J. Atmos. Oceanic. Technol., 22, 225-246.

Greenhut, G. K., and S. J. S. Khalsa, 1982: Updraft and downdraft events in the atmospheric boundary layer over the equatorial Pacific Ocean. J. Atmos. Sci., 39, 1803-1818.

Grossman, R. L., 1984: Bivariate conditional sampling of moisture flux over a tropical ocean. J. Atmos. Sci., 41, 3238-3254.

Houze, R. A., 1993: Cloud Dynamics. Academic Press, 573 pp.

- 1997: Stratiform precipitation in regions of convection: A meteorological paradox? Bull. Amer. Meteor. Soc., 78, 21792196.

Kelly, R. D., 1982: A single Doppler radar study of horizontal-roll convection in a lake-effect snow storm. J. Atmos. Sci., 39, 1521-1531.

_ 1984: Horizontal roll and boundary-layer interrelationships observed over Lake Michigan. J. Atmos. Sci., 41, 1816-1826.

Kristovich, D. A. R., N. F. Laird, M. R. Hjelmfelt, R. G. Derickson, and K. Cooper, 1999: Transitions in boundary layer meso- $\gamma$ convective structures: An observational case study. Mon. Wea. Rev., 127, 2895-2909.

_ , and Coauthors, 2000: The lake-induced convection experiment and the snowband dynamics project. Bull. Amer. Meteor. Soc., 81, 519-542.

—, N. F. Laird, and M. R. Hjelmfelt, 2003: Convective evolution across Lake Michigan during a widespread lake-effect snow event. Mon. Wea. Rev., 131, 643-655.

Kuettner, J. P., 1971: Cloud bands in the Earth's atmosphere: Observation and theory. Tellus, 23, 404-425.

LeMone, M. A., 1973: The structure and dynamics of horizontal roll vortices in the planetary boundary layer. J. Atmos. Sci., 30, 1077-1091.

- 1990: Some observations of vertical velocity skewness in the convective planetary boundary layer. J. Atmos. Sci., 47, 1163-1169.

_ , and A. Pennell, 1976: Relationship of trade wind cumulus distribution to subcloud layer fluxes and structure. Mon. Wea. Rev., 104, 524-553.

Lenschow, D., 1972: The measurement of air velocity and temperature using the NCAR Buffalo Aircraft Measuring system. NCAR Tech. Note NCAR/TN-EDD-75, 39 pp.

Locatelli, J. D., and P. V. Hobbs, 1974: Fallspeeds and masses of solid precipitation particles. J. Geophys. Res., 79, 2185-2197.

Miao, Q., B. Geerts, and M. A. LeMone, 2006: Vertical velocity and buoyancy characteristics of coherent echo plumes in the convective boundary layer, detected by a profiling airborne radar. J. Appl. Meteor. Climatol., 45, 838-855.

Miura, Y., 1986: Aspect ratio of longitudinal rolls and convection cells observed during cold-air outbreaks. J. Atmos. Sci., 43, 26-39. 
Mourad, P. D., and B. A. Walter, 1996: Satellite scatterometer evidence of roll circulations in the marine atmospheric boundary layer. J. Geophys. Res., 101, 16 391-16 400.

Pazmany, A., R. McIntosh, R. Kelly, and G. Vali, 1994: An airborne $95 \mathrm{GHz}$ dual-polarized radar for cloud studies. IEEE Trans. Geosci. Remote Sens., 32, 731-739.

Rao, G.-S., and E. M. Agee, 1996: Large eddy simulation of turbulent flow in a marine convective boundary layer with snow. J. Atmos. Sci., 53, 86-100.

Squires, P., and J. S. Turner, 1962: An entraining jet model for cumulonimbus updraughts. Tellus, 14, 422-434

Stull, R. B., 1988: An Introduction to Boundary Layer Meteorology. Kluwer Academic, $666 \mathrm{pp}$.

Sykes, R. I., and D. S. Henn, 1989: Large-eddy simulation of turbulent sheared convection. J. Atmos. Sci., 46, 1106-1118.

Walter, B. A., and J. E. Overland, 1984: Observations of longitudinal rolls in a near neutral atmosphere. Mon. Wea. Rev., 112, 200-208.
Weckwerth, T. M., J. W. Wilson, and R. M. Wakimoto, 1996: Thermodynamic variability within the convective boundary layer due to horizontal convective rolls. Mon. Wea. Rev., 124, 769-784.

,,$-- \ldots$, and N. A. Crook, 1997: Horizontal convective rolls: Determining the environmental conditions supporting their existence and characteristics. Mon. Wea. Rev., 125, 505526.

_ T. W. Horst, and J. W. Wilson, 1999: An observational study of the evolution of horizontal convective rolls. Mon. Wea. Rev., 127, 2160-2179.

Young, G. S., 1988: Turbulence structure of the convective boundary layer. Part II: Phoenix 78 aircraft observations of thermals and their environment. J. Atmos. Sci., 45, 727-735.

- D. A. R. Kristovich, M. R. Hjelmfelt, and R. C. Foster, 2002: Rolls, streets, waves, and more: A review of quasi-twodimensional structures in the atmospheric boundary layer. Bull. Amer. Meteor. Soc., 83, 997-1001. 